\title{
Novelty and fear conditioning induced gene expression in high and low states of anxiety
}

\author{
Melanie P. Donley and Jeffrey B. Rosen \\ Department of Psychological and Brain Sciences, University of Delaware, Newark, Delaware 19716, USA
}

\begin{abstract}
Emotional states influence how stimuli are interpreted. High anxiety states in humans lead to more negative, threatening interpretations of novel information, typically accompanied by activation of the amygdala. We developed a handling protocol that induces long-lasting high and low anxiety-like states in rats to explore the role of state anxiety on brain activation during exposure to a novel environment and fear conditioning. In situ hybridization of the inducible transcription factor Egr-1 found increased gene expression in the lateral nucleus of the amygdala (LA) following exposure to a novel environment and contextual fear conditioning in high anxiety-like rats. In contrast, low state anxiety-like rats did not generate Egr-1 increases in LA when placed in a novel chamber. Egr-1 expression was also examined in the dorsal hippocampus and prefrontal cortex. In CAl of the hippocampus and medial prefrontal cortex (mPFC), Egr-l expression increased in response to novel context exposure and fear conditioning, independent of state anxiety level. Furthermore, in mPFC, Egr-l in low anxiety-like rats was increased more with fear conditioning than novel exposure. The current series of experiments show that brain areas involved in fear and anxiety-like states do not respond uniformly to novelty during high and low states of anxiety.
\end{abstract}

Emotional states influence the manner in which stimuli and events are interpreted. Humans interpret ambiguous emotional stimuli congruent with their emotional state at the time of testing (Byrne and Eysenck 1993; Halberstadt et al. 1995; Niedenthal and Setterlund 1994, 1997). For instance, anxiety level affects the interpretation of ambiguous information (Mathews et al. 1989; Eysenck et al. 1991; Richards et al. 2002). Higher state and trait anxiety is associated with adopting a threatening, or more negative, interpretation of ambiguous information (Mathews et al. 1989; Eysenck et al. 1991; Blanchette and Richards 2003; Blanchette et al. 2007), and anxious individuals have high estimates of personal danger (Butler and Mathews 1983).

The human literature suggests that fear and state anxiety are mediated by the same neural circuitry responsible for overt states of fear which have been delineated with Pavlovian conditioning in animals (Davis 1997; Ledoux 2000; Maren 2001). In particular, human imaging studies have shown that the amygdala is activated during fear conditioning (Furmark et al. 1997; LaBar et al. 1998; Phelps et al. 2001), just as immediate-early gene expression is during fear conditioning in rodents (Beck and Fibiger 1995; Rosen 2004; Ploski et al. 2010; Cruz et al. 2013; Veyrac et al. 2014; Gouty-Colomer et al. 2015). In addition to fear conditioning, the amygdala is activated during detection of novelty, particularly those stimuli with biological relevance like human faces and snakes (Wright et al. 2003, 2008; Blackford et al. 2010; Balderston et al. 2011). It is important to detect and assess novel stimuli and environments for their potential danger, reward or neutrality, suggesting that the amygdala is involved not only during learning of explicit fear conditioning, but also during assessment of uncertain, novel stimuli and situations. The amount of activation of the amygdala during novelty detection is also positively correlated to state and trait anxiety (Schwartz et al. 2003; Somerville et al. 2004; Blackford et al. 2009, 2011, 2013;

\section{Corresponding author: jrosen@udel.edu}

Article is online at http://www.learnmem.org/cgi/doi/10.1101//m.044289. 116.
Balderston et al. 2011, 2013), but novelty detection might also be independent of trait anxiety (Pedersen et al. 2017). Interestingly, when a reliable fear stimulus and nonfear relevant stimulus (novel pictures of snakes and flowers, respectively) are presented in the same test session, both snakes and flowers induce amygdala BOLD fMRI activity, suggesting that threatening stimuli (e.g., snakes) prime the amygdala to respond to nonfear relevant stimuli too (Pedersen et al. 2017).

In rats, while the amygdala is activated during states of overt fear, such as those induced by Pavlovian fear conditioning, it has been difficult to differentiate whether the amygdala is activated during uncertainty and novelty-anxious states that do not reach the level of overt fear. This is exemplified in contextual fear conditioning studies which find increased expression of the inducible plasticity-associated immediate early gene early growth response gene-1 (Egr-1 also called krox-24, TIS 8, NGFI-A, zif268, ZENK) in the lateral nucleus of the amygdala (LA) following fear conditioning (Rosen et al. 1998; Hall et al. 2000; Malkani and Rosen 2000). In these studies, a novelty control group is placed in the novel test chamber but does not receive a shock. In one study Egr-1 in the LA is increased in both the novelty and fear conditioning groups (Hall et al. 2000), whereas the other studies do not find increased Egr-1 in the LA in this novelty group (Rosen et al. 1998; Malkani and Rosen 2000). The discrepancy between studies is important issue to resolve if our neurobehavioral animal models of the function of the amygdala are to be relevant to humans (Rosen and Donley 2006). It may be possible that in some experiments the rats were in a higher anxiety-like state prior to exposure to novel chamber (Hall et al. 2000) than in other experiments (Rosen et al. 1998; Malkani and Rosen 2000).

(C) 2017 Donley and Rosen This article is distributed exclusively by Cold Spring Harbor Laboratory Press for the first 12 months after the full-issue publication date (see http://learnmem.cshlp.org/site/misc/terms.xhtml). After 12 months, it is available under a Creative Commons License (Attribution-NonCommercial 4.0 International), as described at http://creativecommons.org/licenses/by-nc/ $4.0 \%$. 
Table 1. Effect of handling environment on behavior in the open field

\begin{tabular}{lcc}
\hline $\begin{array}{l}\text { Handling } \\
\text { condition }\end{array}$ & $\begin{array}{c}\text { Number of } \\
\text { crosses }\end{array}$ & $\begin{array}{c}\text { Time spent in center } \\
(\mathrm{sec})\end{array}$ \\
\hline Quiet & $133.5 \pm 9.09$ & $17.5 \pm 2.70^{*}$ \\
Noisy & $125.0 \pm 9.53$ & $34.1 \pm 6.54$ \\
\hline
\end{tabular}

Handling environment had no effect on locomotor activity in the open field, indicated by the number of crosses made. However, rats handled in a noisy environment spent significantly more time in the center of the open field than rats handled in a quiet environment (difference denoted by *).

To address the role of the amygdala in novelty and uncertainty, we designed the present series of experiments to investigate whether the rat LA and other associated regions which are involved in novelty and fear (hippocampus and medial prefrontal cortex) (Tulving et al. 1996; Grunwald et al. 1998; Menon et al. 2000; Daselaar et al. 2006; Bishop 2007; Kirwan et al. 2009; Lever et al. 2010; Satpute et al. 2013; Bannerman et al. 2014) are activated differentially to novelty and overt fear, during low and high levels of state anxiety. We hypothesize that, in rats, as in humans, statelike anxiety facilitates the activation of the amygdala to novel situations. In humans, state anxiety can be influenced by a number of situational factors. In rats, state-like anxiety can be modulated by preexperimental handling (Dobrakovová et al. 1993). Following handling that either induces a high or low level of state-like anxiety, activation of various brain regions during novelty and fear conditioning using expression of the immediate early gene Egr-1, can be measured. Preliminary results of some of the data were previously published in a review format (Rosen and Donley 2006).

\section{Results}

\section{Experiment 1: handling environment influences open field behavior}

To see if we could induce a high and low anxiety-like states in random groups of rats, rats were handled for $1 \mathrm{wk}$ in either a noisy or a quiet environment (handling conditions are described in detail in the Materials and Methods). The following day after handling, behavior of rats was analyzed in an open field, a measure of locomotion and anxiety-like behavior. A total of 16 experimentally naïve rats were used in this study, 8 rats each assigned to the noisy and quietly handled groups. One animal was removed from each handling condition because a computer malfunction prevented the video from being saved. One additional animal was removed from the quiet condition after behavioral results were more than 2 SDs away from the group mean, leaving 6 animals in the quiet group and 7 animals in the noisy group. Results are shown in Table 1 . Handling condition did not significantly affect the number of crosses made in the open field and therefore did not significantly affect this measure of locomotor activity $\left(F_{(1,11)}<1\right.$, NS). However, when measuring time spent within the center squares of the field, rats handled in noisy conditions spent significantly more time in the center of the open field than rats handled in the quiet $\left(F_{(1,11)}=4.892, P<0.05\right)$, indicating a lower level of anxiety-like behavior.

\section{Experiment 2: handling environment-induced state-like anxiety does not affect contextual fear conditioning}

Next, we tested whether handling environment has differential effects on fear learning, retention, and extinction of contextually conditioned fear. Thirty-two experimentally naïve rats were used in this experiment, eight rats in each of the four groups (Noisy context, Noisy fear conditioning, Quiet context, Quiet fear conditioning). As described in more detail in the Materials and Methods, rats were handled either in a noisy or quiet environment. Rats were then either placed in a fear conditioning chamber for $7 \mathrm{~min}$ without receiving footshock (context condition) or received a 1-sec $1.5-\mathrm{mA}$ footshock $3 \mathrm{~min}$ after being placed in chamber and remained in chamber for another 4 min (fear conditioning). Rats were returned to the chamber $24 \mathrm{~h}$ later for a retention test, and then several extinction tests the following days. The results are shown in Figure 1. A one-way ANOVA comparing freezing behavior in the noisy and quiet context and conditioned groups during the first 3 min of chamber exposure (preshock period) showed that there was no difference in freezing behavior upon placement in the chambers $\left(F_{(3,28)}<1, \mathrm{NS}\right)$. A repeated-measures ANOVA [2 between factors: group (context vs. conditioned) and handling condition (noisy vs. quiet); one within factor: time (postshock vs. retention)] revealed a significant main effect for group $\left(F_{(1,28)}=204.42, P<0.0005\right)$, no effect for handling condition $\left(F_{(1,28)}=1.23\right.$, NS), and no group by handling condition interaction $\left(F_{(1,28)}=1.03, \mathrm{NS}\right)$. In general, rats that were conditioned showed significantly more freezing than rats in the context groups, regardless of handling condition. In addition, there was a significant time by group interaction $\left(F_{(1,28)}=6.49, P<0.05\right)$, no time by handling condition interaction $\left(F_{(1,28)}<1\right.$, NS) and no time by group by handling condition interaction $\left(F_{(1,28)}<1, \mathrm{NS}\right)$. Rats in the context exposure group showed virtually no freezing following initial context exposure, or during reexposure to the chamber $24 \mathrm{~h}$ later. Handling environment had no effect on freezing in context-exposed rats. Rats that were fear conditioned showed virtually no preshock freezing, much like the context group. However, conditioned rats showed robust freezing during the post-shock period, and high levels of freezing during retention, regardless of handling environment. There was also no effect of handling environment on retention for fear conditioning. Because the context animals did not show freezing during their first exposure to chamber, nor during a retention test, they were not tested for extinction beyond retention day. However, because extinction freezing can reflect the strength of learning, $3 \mathrm{~d}$ of extinction were performed on the fearconditioned animals to see whether handling condition would have an effect on the rate of extinction learning. A repeatedmeasures ANOVA (between measure: handling condition; within measure: time) was performed on the day of retention and the $3 \mathrm{~d}$ of extinction. The ANOVA revealed no effect of handling condition $\left(F_{(1,14)}<1\right.$, NS), a significant main effect of time $\left(F_{(2,28)}=\right.$

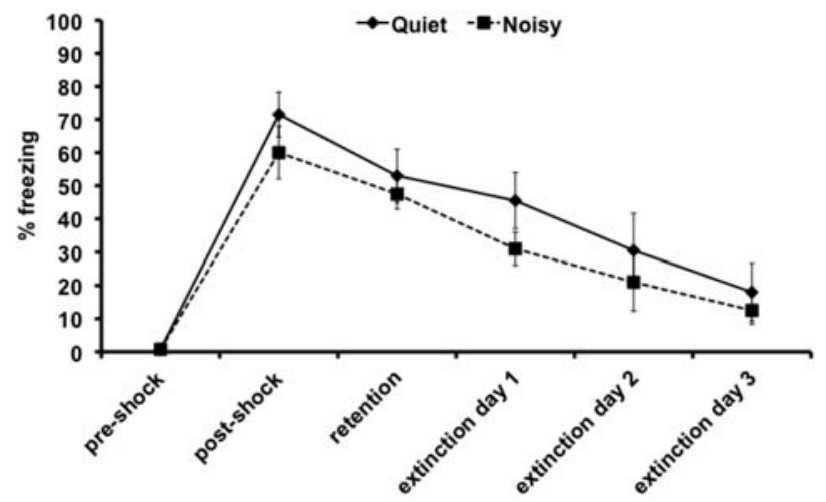

Figure 1. No effects of handling condition on fear conditioning, retention, and extinction. Fear conditioning induced robust freezing, with no significant effect of handling environment (quiet, noisy) on freezing prior to or following fear conditioning, nor during retention or extinction tests. 
22.19, $P<0.0005)$, and no handling condition by time interaction $\left(F_{(2,28)}<1, \mathrm{NS}\right)$. Overall, handling condition had no effect on freezing behavior prior to footshock, immediately after footshock, nor in the retention and extinction tests.

Because 1.5-mA footshock is quite strong and might have obscured a subtler effect of state-like anxiety on contextual fear conditioning, the experiment was repeated but with a $0.6-\mathrm{mA}$ 1 -sec footshock in eight noisy and eight quiet-handled rats. Both groups displayed the same levels of freezing during post-shock, retention and extinction testing (data not shown). Thus, the lack of an effect of noisy and quiet handling on contextual fear conditioning was replicated with a lower current shock.

\section{Experiment 3: state-like anxiety does not affect basal Egr-1 expression in amygdala and hippocampus}

This experiment was done to determine whether basal Egr-1 expression, that is, without exposure to testing chambers, in the LA and the hippocampus varied with handling condition (statelike anxiety level). Brain sections of handled animals from quiet and noisy handling experiments ( $n=8$, each group) were analyzed on the same film for a direct comparison of basal Egr-1 expression. In the LA, a one-way ANOVA performed on the standardized $\mathrm{nCi} / \mathrm{g}$ densities showed that there was no significant difference in basal Egr-1 expression due to state-like anxiety level $\left(F_{(1,14)}=2.73\right.$, NS) (data not shown).

In the hippocampus (CA1, CA3, DG) there were no significant differences in handling on basal Egr-1 expression in any of the three regions of hippocampus, analyzed by one-way ANOVAs (CA1, $F_{(1,14)}=1.507$, NS; CA3, $F_{(1,14)}=1.766$, NS; DG, $F_{(1,14)}<1$, NS) (data not shown). Therefore, handling environment, whether noisy or quiet, had no observable effect on basal levels of Egr-1 expression in either the LA or hippocampus after $7 \mathrm{~d}$ of handling.

\section{Experiment 4: state-like anxiety differentially affects Egr-1 expression to novelty but not fear conditioning}

Experiment 4a: novelty does not induce amygdala Egr-1 expression in animals with low state-like anxiety (noisy handling)

To examine the effects of state-like anxiety during exposure to novelty and fear conditioning in the brain, a total of 24 rats were used, with 8 animals in each of the 3 groups. Similar to the fear conditioning experiments of Experiment 2, animals in the context group showed virtually no freezing while in the chambers (mean of time spent freezing: $1 \%)$. In contrast, rats in the conditioned group showed robust freezing in the $4 \mathrm{~min}$ following the footshock (mean: 79.5\%).

Expression of $E g r-1$ was examined in the LA. Representative autoradiographs and a graphical representation of mean standardized densities, converted to percent of the handled group, are shown in Figure 2. A one-way ANOVA of Egr-1 expression revealed a significant group effect $\left(F_{(2,21)}=8.04, P<0.005\right)$. A StudentNewman-Keuls post hoc test revealed that while Egr-1 expression in the LA of the handled and context groups did not differ, both groups had significantly lower $E g r-1$ levels of expression than the conditioned group. The mean expression of Egr-1 in the LA of the conditioned group sion from Elsevier (C) 1998.) was $54 \%$ and $30 \%$ greater than the handled and context groups, respectively. Therefore, Egr-1 mRNA was significantly increased in the LA following fear conditioning, but not after exposure to a novel context in low state anxiety-like animals handled in a noisy environment. These results replicate those of Rosen et al. (1998) and Malkani and Rosen (2000).

Expression of Egr-1 was also examined in CA1, CA3, and DG in the dorsal hippocampus. Representative autoradiographs and graphical representations of Egr-1 expression in CA1, CA3, and DG are shown in Figure 3. Each region of the hippocampus was analyzed separately. In the CA1, a one-way ANOVA revealed a significant group effect $\left(F_{(2,21)}=4.17, P<0.05\right)$. A Student-NewmanKeuls post hoc test showed that Egr-1 in the handled group was significantly lower than both the context and conditioned groups. The context and conditioned groups, however, were not significantly different. In CA3 and DG, there were no significant differences between groups, $F_{(2,21)}<1$, NS and $F_{(2,21)}<1$, NS, respectively.

Expression of Egr-1 was examined in the prelimbic (PL) and infralimbic (IL) regions of the medial prefrontal cortex. Representative autoradiographs and graphical representations of Egr-1 expression in PL and IL are shown in Figure 4. In the PL, a one-way ANOVA revealed a significant group effect $\left(F_{(2,21)}=\right.$ $26.72, P<0.0001)$. A Student-Newman-Keuls post hoc test showed that the handled group had Egr-1 expression that was significantly lower than both the context and conditioned groups. The context group was significantly lower than the conditioned group. In the IL, the results were the same: a one-way ANOVA revealed a significant group effect $\left(F_{(2,21)}=22.63, P<0.0001\right)$. A Student-NewmanKeuls post hoc test showed that the handled group had Egr-1 expression that was significantly lower than both the context and conditioned groups. The context group was significantly lower than the conditioned group.

\section{Experiment 4b: novelty induces amygdala Egr-1 expression in animals with high state-like anxiety (quiet handling)}

A total of 24 rats were also used in this experiment, with 8 rats in each of the 3 groups. However, one brain of a rat in the fearconditioned group was damaged during sacrifice and was therefore not used in the Egr-1 analysis. Again, animals in the context group showed virtually no freezing while in the chambers (mean: $1.5 \%$ ),
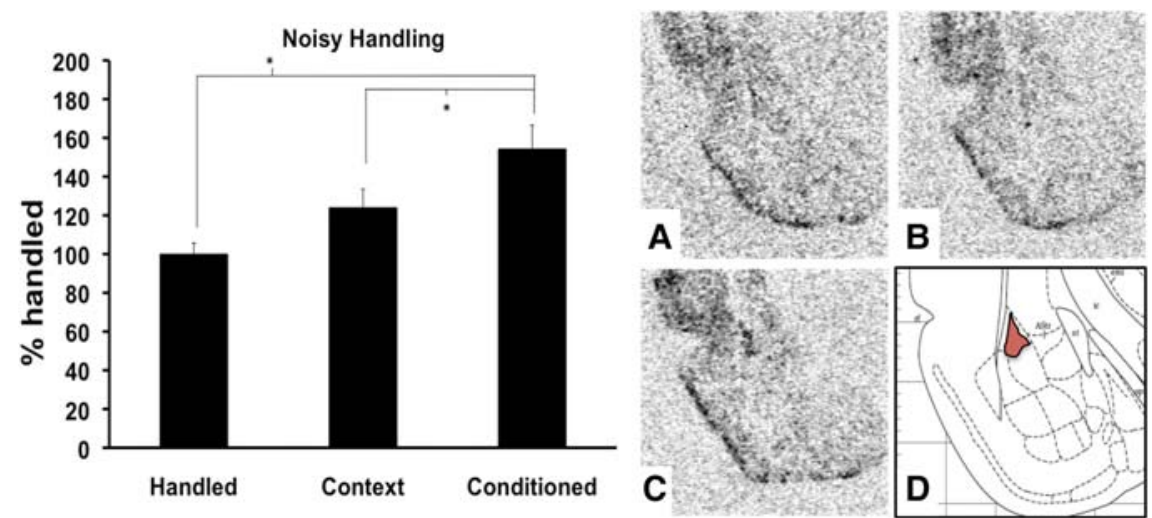

Figure 2. Mean Egr-1 expression in the LA of rats handled in a noisy environment converted to percent of the handled group. Fear-conditioned rats had significantly higher levels of Egr-1 expression in the LA than animals in both the handled and context groups, as denoted by asterisks. The handled and context groups were not different. Representative autoradiographs of Egr-1 expression in the LA of animals handled in a noisy environment for the $(A)$ handled, $(B)$ context, and $(C)$ conditioned groups. (D) Representative diagram of LA (shaded in red). (Reprinted from Paxinos and Watson 1998, with permis- 


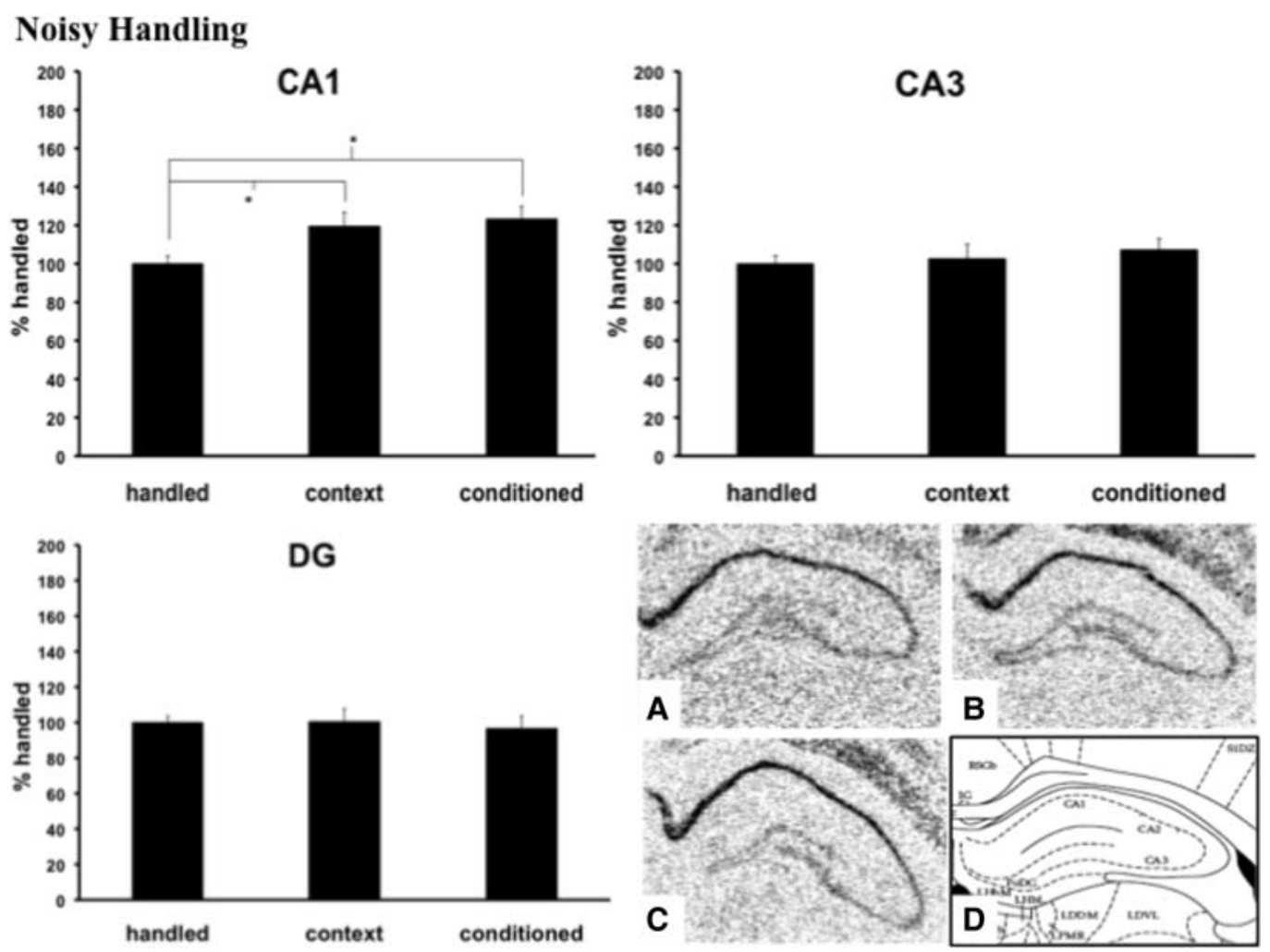

Figure 3. Mean Egr-1 expression in the dorsal hippocampus of rats handled in a noisy environment converted to percent of the handled group. In CA1, animals that were exposed to a novel context and those that were fear conditioned had significantly higher levels of Egr-1 expression than animals in the handled group, as denoted by asterisks. The context and conditioned groups were not different. In CA3 and DG, there were no significant differences between groups. Representative autoradiographs of Egr-1 expression in the dorsal hippocampus of animals handled in a noisy environment for the (A) handled, $(B)$ context, and $(C)$ conditioned groups. $(D)$ Representative diagram of dorsal hippocampus. (Reprinted from Paxinos and Watson 1998, with permission from Elsevier (C) 1998.)

while rats in the conditioned group showed robust freezing in the 4 min following the footshock (mean: $80.5 \%$ ).

Expression of Egr-1 was examined in the LA. Representative autoradiographs and a graphical representation of mean standardized densities, converted to percent of the handled group, are shown in Figure 5. One animal from the context group was not used because the film image was blurry. A one-way ANOVA of Egr-1 expression revealed a significant group effect $\left(F_{(2,19)}=26.324, P<0.0005\right)$. A Student-Newman-Keuls post hoc test revealed that the handled group was significantly different from both the context and fear-conditioned groups. The context and fear-conditioned groups were not significantly different. The context group had a mean increase in Egr-1 expression of 51\% $( \pm 8.08 \%)$ over handled animals, while the fear-conditioned group had a mean increase of $70 \%( \pm 9.62 \%)$ over the handled group. Therefore, after handling in a quiet environment (high state-like anxiety), both context and conditioned animals showed significant increases in Egr-1 expression in the LA compared with the handled group. These results replicate those of Hall et al. (2000).

Expression of Egr-1 was examined in CA1, CA3, and DG in the dorsal hippocampus. Representative autoradiographs and graphical representations of Egr-1 expression in CA1, CA3, and DG are shown in Figure 6. In the dorsal hippocampus, a one-way ANOVA found a significant group effect in area CA1 $\left(F_{(2,19)}=5.281, P<0.05\right)$. A Student-Newman-Keuls post hoc test showed that the handled group was significantly different from the conditioned and context groups, while the conditioned and context groups were not different. In areas CA3 and DG, one-way ANOVAs found no significant differences (DG, $F_{(2,19)}=1.75$, NS), although there was a trend toward significance in CA3 (CA3,
$\left.F_{(2,19)}=3.48, P=0.053\right)$. Thus, the high and low anxious rats had similar increases in Egr-1 expression in the hippocampus.

A total of 24 rats were used, with 8 animals in each of the 3 groups. As mentioned in previous chapters, animals in the context group showed virtually no freezing while in the chambers (mean: $1 \%$ ), while rats in the fear-conditioned group showed robust freezing in the $4 \mathrm{~min}$ following footshock (mean: $79.5 \%$ ).

Expression of $E g r-1$ was examined in the PL and IL regions of the mPFC. Representative autoradiographs and graphical representations of mean standardized densities, converted to percent of the handled group, are shown in Figure 7. In the PL region of the mPFC, a one-way ANOVA revealed a significant group effect $\left(F_{(2,19)}=4.301, P<0.05\right)$. A Student-Newman-Keuls post hoc test showed that the handled group had Egr-1 expression that was significantly lower than both the context and conditioned groups. The context and conditioned groups were not significantly different. In the IL region of the MPFC, the results were the same: a one-way ANOVA revealed a significant group effect $\left(F_{(2,19)}=5.859, P<0.05\right)$. A Student-Newman-Keuls post hoc test showed that the handled group had Egr-1 expression that was significantly lower than both the context and conditioned groups. The context and conditioned groups were not significantly different. Therefore, handling environment creates a differential Egr-1 response profile in the brain in response to novelty.

\section{Discussion}

Detection of novelty is important for assessment of whether new stimuli, events, and situations are potentially threatening, 


\section{Noisy Handling}
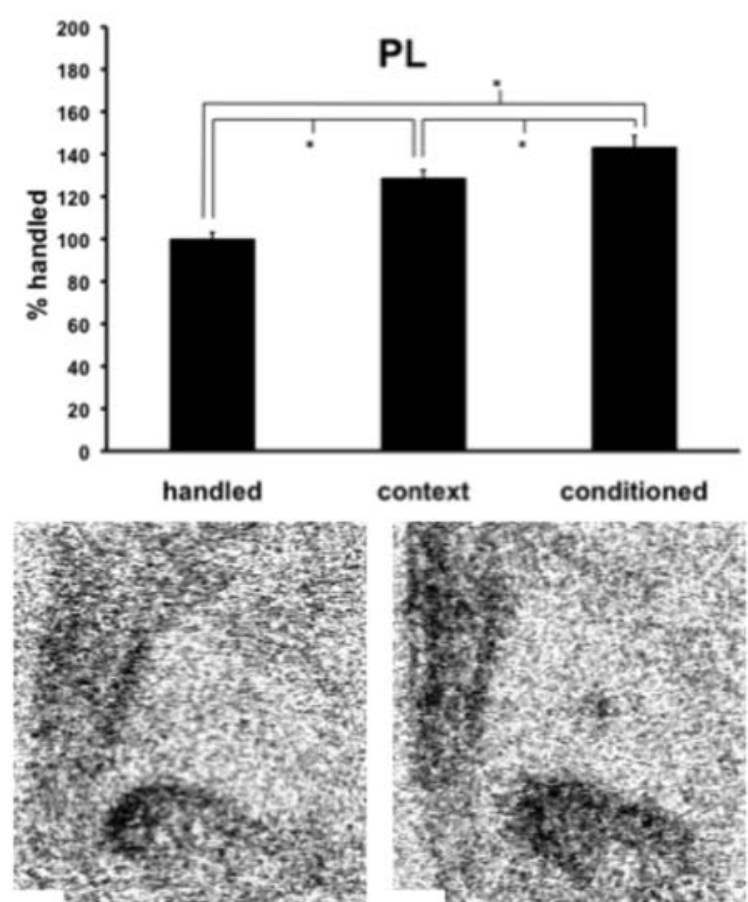

A
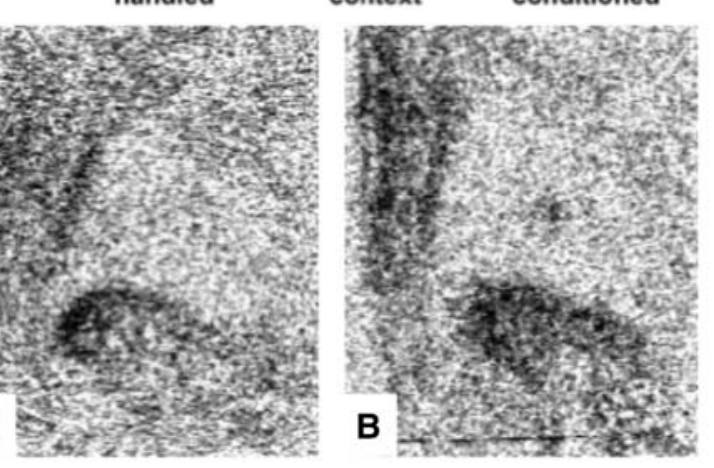
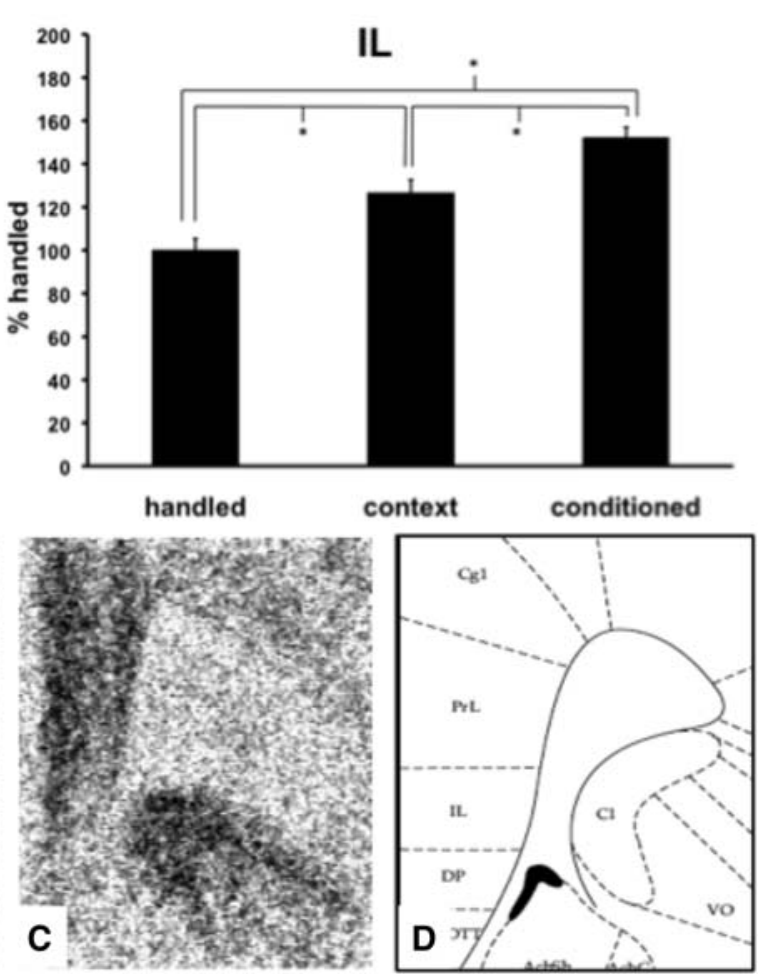

Figure 4. Mean Egr-1 expression in the prefrontal cortex of rats handled in a noisy environment converted to percent of the handled group. Animals that were fear conditioned had significantly higher levels of Egr-1 expression in the PL and IL than animals in both the handled and context groups. The handled and context groups were also significantly different. Significant differences between groups are denoted by asterisks. Representative autoradiographs of Egr-1 expression in the mPFC of animals handled in a noisy environment for the $(A)$ handled, $(B)$ context, and $(C)$ conditioned groups. $(D)$ Representative diagram of mPFC. (Reprinted from Paxinos and Watson 1998, with permission from Elsevier (C) 1998.)

rewarding or neutral (Pedersen et al. 2017). Assessment of novelty is also proposed to be an early stage in long-term memory encoding of meaning-based information (Tulving et al. 1996). In this regard, the emotional state likely influences the assessment of novelty and learning of novel associates. In humans, trait and state anxiety influences the detection and assessment of novel stimuli and the activity of brain regions associated with fear and anxiety (Schwartz et al. 2003; Somerville et al. 2004; Blackford et al. 2009, 2011, 2013; Balderston et al. 2013). We developed a handling protocol in rats to induce longlasting state-like anxiety and tested whether high or low state-like anxiety influenced neural activation in the amygdala, hippocampus, and medial prefrontal cortex. To reduce the influence of traitlike anxiety and individual differences, we randomly assigned rats to handling in either a noisy or quiet environment.

Our experiments demonstrate that handling environment does not affect overt fear-conditioned freezing or increase nonconditioned freezing in a novel small chamber. Because the test chamber is small, other behaviors beside freezing and no-freezing are difficult to measure. No-freezing behaviors are typically head movements and sniffing, but not large body movements, like locomotion and rearing. However, handling environment does influence behavior in more subtle tests of fear and anxiety that allow for the generation of a number of exploratory and defensive behaviors. In a novel large open field test, handling environment influenced time spent in the center of an

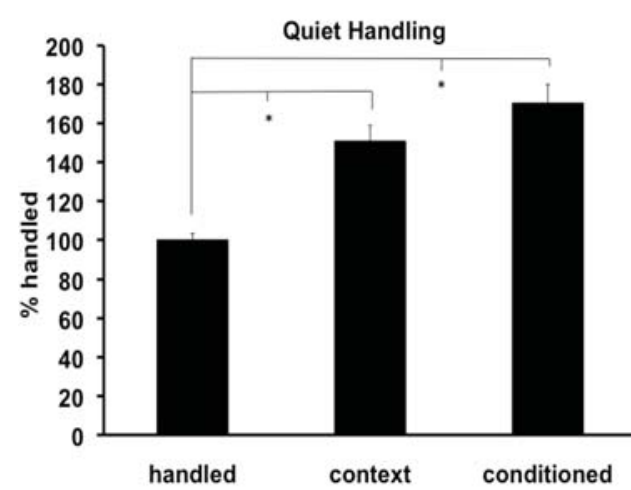

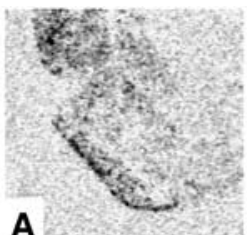
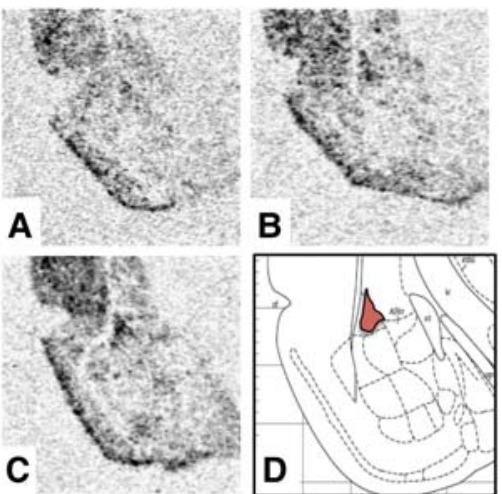

Figure 5. Mean Egr-1 expression in the LA of rats handled in a quiet environment converted to percent of the handled group. Animals that were exposed to a novel context and those that were fear conditioned had significantly higher levels of Egr-1 expression in the LA than animals in the handled group, as denoted by asterisks. The context and conditioned groups were not different. Representative autoradiographs of Egr-1 expression in the LA of animals handled in a quiet environment for the $(A)$ handled, $(B)$ context, and $(C)$ conditioned groups. $(D)$ Representative diagram of LA (shaded in red). (Reprinted from Paxinos and Watson 1998, with permission from Elsevier (C) 1998.) 


\section{Quiet Handling}
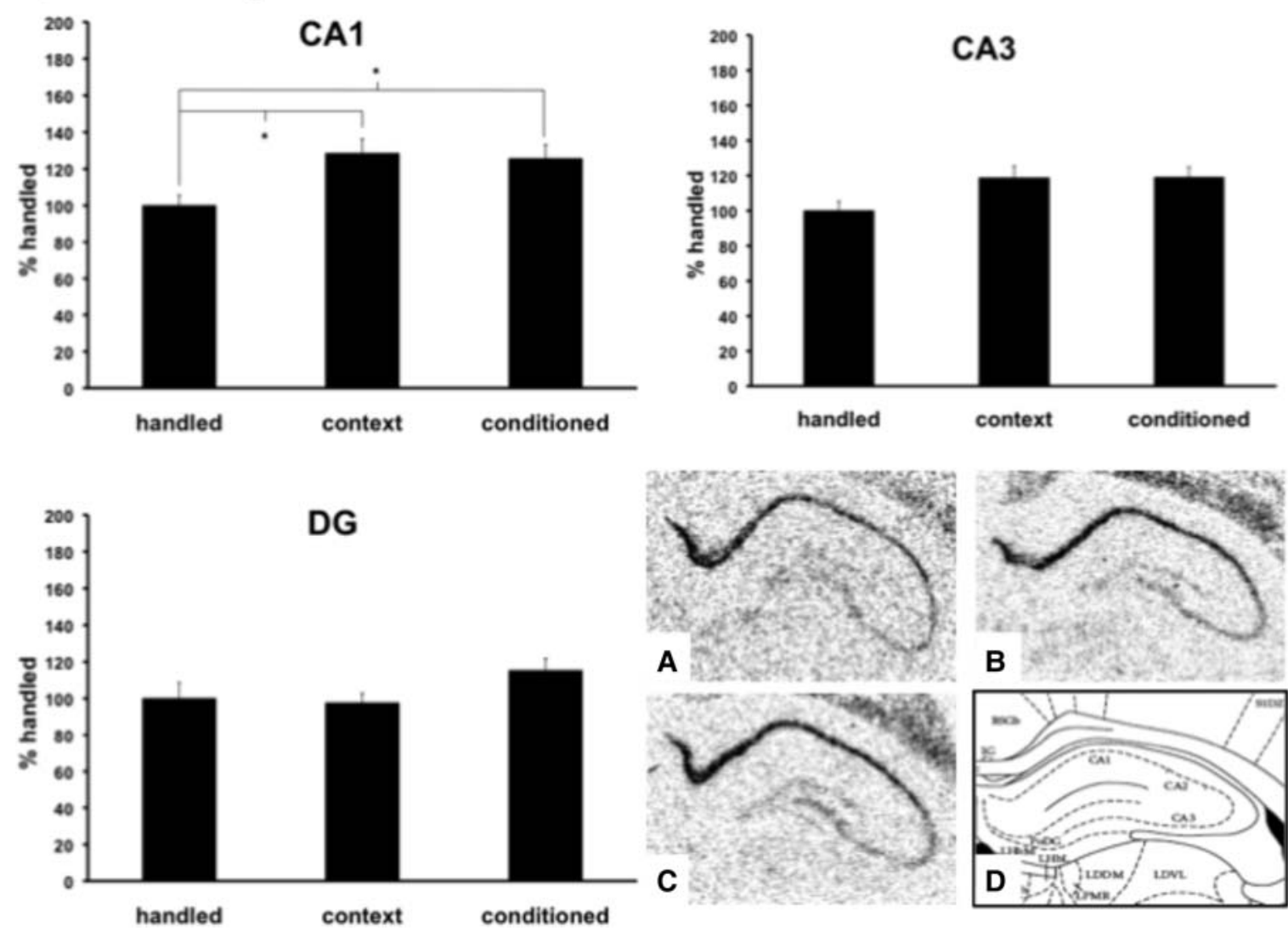

A

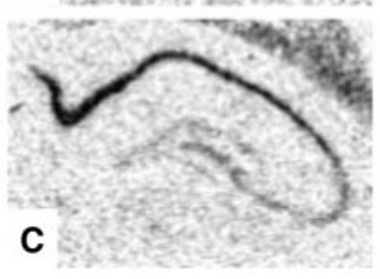

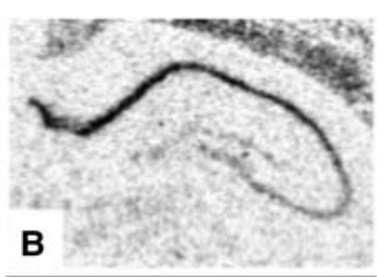

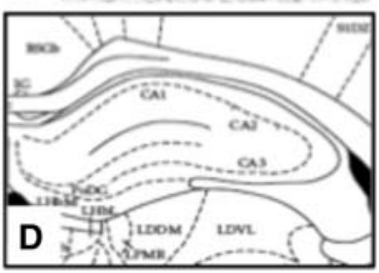

Figure 6. Mean Egr-1 expression in the dorsal hippocampus of rats handled in a quiet environment converted to percent of the handled group. In CA1, animals that were exposed to a novel context and those that were fear conditioned had significantly higher levels of Egr-1 expression than animals in the handled group, as denoted by asterisks. The context and conditioned groups were not different. In CA3 and DG, there were no significant differences between groups. Representative autoradiographs of Egr-1 expression in the dorsal hippocampus of animals handled in a quiet environment for the ( $A$ ) handled, (B) context, and (C) conditioned groups. (D) Representative diagram of dorsal hippocampus. (Reprinted from Paxinos and Watson 1998, with permission from Elsevier (C) 1998.)

open field, without altering locomotor activity. Quiet-handled rats spent significantly less time in the center of the open field than noisy-handled rats. While the open field test can be criticized for its poor discriminate validity (Ennaceur 2014), less time spent in the center of the open field is typically regarded as an index of higher anxiety-like behavior (McCarthy et al. 1995; Paylor et al. 2006). This suggests that quiet-handled animals have significantly higher levels of state-like anxiety than noisy-handled animals. In the same vein, increased time in the center of the field allowing for more exploration suggests low state-like anxiety in noisyhandled rats.

We initially thought handling in a quiet environment would induce lower state-like anxiety, but the opposite occurred. It is possible that exposure to loud, unpredictable changes in noise while being safely handled by a human produces resilience for future novel experiences in adult male rats. Other types of manipulations have been shown to affect state-like anxiety as well. Environmental enrichment in rodents influences subsequent anxious and fear behavior. For instance, animals exposed to enriched environments show lower levels of anxiety-like behavior than rats housed in standard cages in both the elevated-plus maze and the open field (Fernández-Teruel et al. 2002; Benaroya Milshtein et al. 2004; Peña et al. 2006), and increases in measures of exploratory activity (Larsson et al. 2002; Widman et al. 1992; Peña et al. 2006). More recently, neonatal handling was shown to reduce anxiety-like and stress responses in a Roman Low
Avoidance rat strain (Río-Álamos et al. 2017). Effects of differential preexperimental handling in adult rats in our paradigm suggest handling in a noisy environment has similar lasting anxiolytic effects (more than $24 \mathrm{~h}$ ) that neonatal handling and environmental enrichment produce.

Our handling effects were not revealed with contextual fear conditioning, suggesting that the effects of state-like anxiety are negated or overridden by contextual fear conditioning. Other manipulations, like environmental enrichment and complex housing, have generally shown facilitation or improvement in fear conditioning (Duffy et al. 2001; Tang et al. 2001; Briand et al. 2005; Barbelivien et al. 2006; Pietropaolo et al. 2014; Clemenson et al. 2015). Why our handling procedure, which was rather limited (5 min per day for a week) compared with most enrichment procedures, was only detectable behaviorally in the open field test, but not with contextual fear conditioning, needs further exploration, as does duration of the handling effect.

\section{Egr-1 expression in the amygdala}

Our results replicate previous studies demonstrating fear conditioning robustly and consistently induces Egr-1 expression in the lateral nucleus of the amygdala (Rosen et al. 1998; Hall et al. 2000; Malkani and Rosen 2000). This occurred in both noisyand quiet-handled rats, corroborating the lack of differential fearconditioned freezing with these handling manipulations (Fig. 1). 


\section{Quiet Handling}
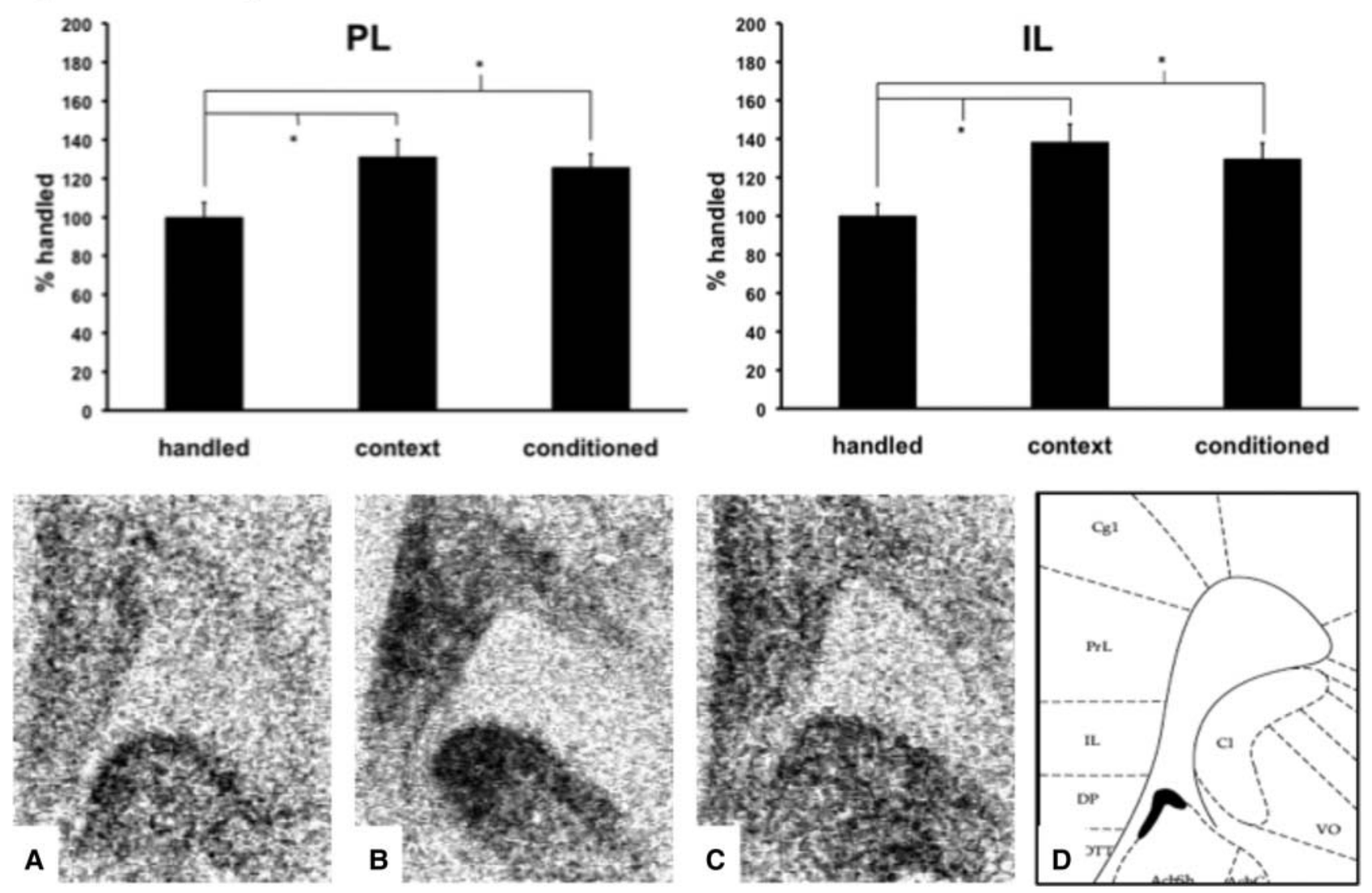

Figure 7. Mean Egr-1 expression in the prefrontal cortex of rats handled in a quiet environment converted to percent of the handled group. Animals that were exposed to the context and rats that were fear conditioned had significantly higher levels of Egr-1 expression in the PL and IL than animals in the handled group. The context and conditioned groups were not significantly different. Significant differences between groups are denoted by asterisks. Representative autoradiographs of Egr-1 expression in the mPFC of animals handled in a quiet environment for the $(A)$ handled, $(B)$ context, and $(C)$ conditioned groups. (D) Representative diagram of mPFC. (Reprinted from Paxinos and Watson 1998, with permission from Elsevier (C) 1998.)

Moreover, handling alone in a noisy or quiet environment for $7 \mathrm{~d}$ did not induce differential basal Egr-1 expression in the LA (Fig. 2). Neither noisy- or quiet-handled rats without exposure to a novel test chamber displayed different levels of Egr-1 in the LA. Thus, neural expression of state-like anxiety, as measured by Egr-1, was only revealed by exposure to a novel experience. Furthermore, the lack of differences in locomotor activity in the open field and minimal freezing in the small chamber in both quiet and noisyhandled rats without shock, suggest that differences in Egr-1 expression in the amygdala to new environments is attributed to different neural responses to novelty, and not to differences in behavior in the two groups of animals.

The present study has important implications for teasing out the neural effects of novelty in fear conditioning paradigms. In immediate-early gene expression studies and studies with other dynamic measures of neural activity with fear conditioning, a control group that experiences the test chamber, but does not receive footshock, is important to determine whether neural activity changes are selective to fear conditioning (Rosen et al. 1999). Published discrepancies in Egr-1 expression in the LA (Rosen et al. 1998; Hall et al. 2000; Malkani and Rosen 2000) generated a discussion about the role of Egr-1 in the LA for learning and memory of fear (Davis et al. 2003; Knapska and Kaczmarek 2004). Our laboratory consistently finds that Egr-1 expression in the LA is robustly expressed in animals following fear conditioning, but not in animals handled or handled and exposed to the conditioning chamber without receiving footshock (Rosen et al. 1998; Malkani and Rosen 2000). Furthermore, rats receiving footshock without fear conditioning have lower levels of Egr-1 expression than fear-conditioned rats (Rosen et al. 1998; Malkani and Rosen 2000). These findings suggest that increased $E g r-1$ expression in the LA is fear conditioning specific. On the other hand, Hall et al. (2000) found Egr-1 expression in the LA was not only increased in fear-conditioned rats, but also in rats exposed to a novel context without footshock, suggesting that Egr-1 is responding to novelty and not fear conditioning per se. The results of the present study replicate findings from both groups and indicate that increased Egr-1 in the LA is neither a specific response to novelty nor to fear conditioning, but can either reflect an emotional state of uncertainty, vigilance when confronted with novel stimuli or part of a mechanism for learning and memory during fear conditioning. A role for Egr-1 in states other than overt fear does not obviate a crucial role for Egr-1 in learning and memory of specific fear because reduction of Egr-1 protein in the LA blocks fear conditioning (Malkani et al. 2004; Maddox et al. 2011).

The amygdala is not only involved in fear, but it is activated during times of heightened vigilance, arousal, and uncertainty (Rosen and Schulkin 1998; Davis and Whalen 2001), and in novel, ambiguous situations (Whalen 1998). Its function is conceptualized in broader terms, operating as part of an environmental 
monitoring system detecting stimuli that may have biological relevance (Whalen 1998; Sander et al. 2003; Janak and Tye 2015). The lateral and basal nuclei of the amygdala have neurons that respond to fear stimuli, safety stimuli, or both (Ostroff et al. 2010; Sangha et al. 2013; Stujenske et al. 2014). Prior experience changes the relevance of stimuli; for example, fear conditioning provides predictive biological relevance of impending danger or harm to previously neutral stimuli, and an amygdala fear circuit is involved in this type of learning (Maren and Fanselow 1996; Davis 1997; LeDoux 2007). Whether the same populations of neurons that respond to novelty in the quiet-handled rats are also responding to fear conditioning is not discernable in our experimental paradigm and the in situ hybridization methods we used. Previous research has shown that amygdala neurons active at the time of fear conditioning are preferentially recruited into the fear engram (Han et al. 2007; Josselyn et al. 2015). We cannot determine this in our studies. Nevertheless, our experiments show that repetitive exposure to an unpredictable, constantly changing noisy environment may produce resiliency and reduce vigilance, arousal, or fear to subsequent novel situations, similar to the effects on rats exposed to enriched environments (Fernández-Teruel et al. 2002; Benaroya Milshtein et al. 2004; Peña et al. 2006). Thus, when exposed to a novel test chamber or environment, the situation may simply be another expected change that does not induce high levels of vigilance and arousal.

Research in both humans and animals has shown that the amygdala is activated to situations that are not only unpredictable, ambiguous, and highly uncertain, (Hsu et al. 2005; Herry et al. 2007; Schultz et al. 2008; Davis et al. 2016), but to novelty itself (Schwartz et al. 2003; Wright et al. 2003, 2008; Blackford et al. 2010; Balderston et al. 2011; Ousdal et al. 2014). However, amygdala activity to novelty is enhanced during states of anxiety (Schwartz et al. 2003; Wright et al. 2003, 2008; Pedersen et al. 2017). Quiet handling might model the generalized effects of high anxiety states in humans, where Egr-1 is increased in the LA during novelty in our experiments. In an opposite manner, noisy handling might produce a conditioned safety experience that generalizes to other novel experiences. Safety learning and safety signals affect amygdala activity differentially from fear conditioning. Fear-conditioned increases in firing in populations of neurons of the LA and basal nucleus of the amygdala are suppressed by conditioned safety signals (Rogan et al. 2005; Sangha et al. 2013) and changes in synapse size and dendritic translational mechanisms in the LA occur in opposite directions with fear and safety conditioning (Ostroff et al. 2010).

On the other hand, when rats are repetitively handled in an acoustically static environment, which induces high levels of statelike anxiety when encountering a new environment, vigilance and arousal are heightened and the amygdala is activated. Along these lines of thought, the repetitive handling in the quiet static environment makes the rats less resilient and prone to increased anxiety-like states. Increased Egr-1 expression in the LA during novel context exposure in quiet-handled rats corroborates this notion.

As suggested by others (e.g., Bishop 2007; Barlow et al. 2014), anxiety involves uncertainty regarding the possibility of threat. In fact, anxious individuals are more likely to interpret neutral stimuli as threatening (Mathews et al. 1989; Eysenck et al. 1991; Blanchette and Richards 2003; Blanchette et al. 2007). Cognitive models of anxiety suggest that anxiety acts to influence a preattentive threat evaluation mechanism (Mathews and Mackintosh 1998; Mogg and Bradley 1998), and that sensitization of the amygdala response to threat-related stimuli plays a role in anxiety (Rosen and Schulkin 1998). Therefore, the sensitivity of an individual to threat-related stimuli may influence the response of the amygdala. This has been demonstrated in phobic individuals shown pictures of the targeted feared stimulus (Öhman and Soares 1994; Larson et al. 2006). Threat-related attentional biases are symptomatic of anxiety and may be involved in the development and maintenance of anxiety disorders. Low or non-anxious individuals either do not show threat-related attentional biases or they have a higher threshold for stimuli to reach before threat detection mechanisms respond and capture attention. In high state anxiety, amygdala activity is high even in the presence of distractors (see Bishop 2008). Moreover, people with inhibited temperament have been shown to be neophobic, showing fear of novelty in the form of increased avoidance responses, perception bias toward interpreting stimuli as threatening, and decreased response time, and increased response amplitude and duration to novelty in the amygdala (Schwartz et al. 2003; Blackford et al. 2009).

In accordance with this idea then, it may be the case that, in animals handled in a quiet environment, higher state-like anxiety predisposes the animal to interpret a novel chamber as possibly threatening, activating the amygdala. Recent human imaging studies support evidence for amygdala activation during times of unpredictability, and a bias toward a negative interpretation of stimuli (Davis et al. 2016).

In conclusion, the current series of studies supports the idea that anxiety is closely linked to states of uncertainty, and that the amygdala is an area of the brain that is linked to processing uncertain stimuli as threatening under high levels of anxiety.

\section{Hippocampus}

The present studies show that Egr-1 in CA1 increases in response to both context exposure and contextual fear conditioning, and state-like anxiety level did not alter these responses. Moreover, exposure to a novel context or contextual fear conditioning does not change Egr-1 levels in either the CA3 or DG regions of the dorsal hippocampus. This is in contrast to previous work that found increased $E g r-1$ in CA3 either nonspecifically in response to footshock (Malkani and Rosen 2000), or in response to both context exposure and fear conditioning (Hall et al. 2000).

Similarity of increased Egr-1 expression in CA1 to both context exposure and contextual fear conditioning is in agreement with a growing body of literature suggesting that the dorsal CA1 specifically encodes context both with and without fear conditioning (Vazdarjanova and Guzowski 2004; Zelikowsky et al. 2014) and appears to be involved in the processing of contextual fear memories (Shimizu et al. 2000), consolidation and long-term memory (Kim et al. 1992; Lee and Kesner 2004; Daumas et al. 2005). Moreover, Egr-1 seems to play a role in the induction and stability of LTP in hippocampus, and shows increases in area CA1 following LTP induction (Mackler et al. 1992; Roberts et al. 1996; Wei et al. 2000). However, infusion of an antisense oligodeoxynucleotide into the CA1 region of the dorsal hippocampus failed to produce retention deficits in fear conditioning in one study (Lee et al. 2004), and our study could not differentiate the Egr-1 response to novelty versus fear conditioning. It appears then, that $E g r-1$ in the CA1 of the hippocampus is involved in contextual processing in response to a novel environment, but we could not determine whether it is involved in the evaluation of threat and fear conditioning processes.

Anxiety-like level does not influence Egr-1 expression in the dorsal hippocampus. However, Egr-1 in the CA1 region of the hippocampus does increase in response to novelty and contextual fear conditioning, regardless of anxiety-like state. Therefore, handling environment and anxiety-like state do not influence the pattern of $E g r-1$ in the same manner as in the lateral amygdala. The results of $E g r-1$ expression in the hippocampus show that differences in Egr-1 expression found in the amygdala is not a result of general expression patterns of $E g r-1$ throughout the whole brain, but rather 
reflects differences in activity and processing in varying areas of the brain. Regardless of handling environment, Egr-1 is increased in animals exposed to a novel context, with or without a footshock. Therefore, it appears as though Egr-1 levels in the dorsal hippocampus (CA1) increase in response to exposure to a novel environment. Similar findings have been found with other immediate-early genes, such as c-fos (Jenkins et al. 2004) and Arc (Guzowski et al. 1999; Zelikowsky et al. 2014). Indeed, other immediate-early genes ( $c$-fos, $c$-jun, fos- $B$ ) have been found to increase in area CA1 in response to spatial novelty and decrease with repeated exposures to the same environment (Papa et al. 1993; Romanelli et al. 2007). In humans, hippocampal activity has been shown to increase in response to novel visual stimuli (Tulving et al. 1996; Grunwald et al. 1998; Menon et al. 2000; Daselaar et al. 2006; Kirwan et al. 2009; Lever et al. 2010; Pedersen et al. 2017) and to decrease following repeated presentations (Fried et al. 1997; Fischer et al. 2003). The increase of hippocampal activity in response to novelty likely reflects processes underlying construction of a contextual map (Mcnaughton et al. 2006; Moser et al. 2008), and once this map has been established, hippocampal activity may again decrease. In our studies, increases in Egr-1 expression in CA1 in animals that were either in the context or the conditioned group may reflect hippocampal processing of a spatial map for the novel environment, without regard to the emotional significance of the experience.

While the present studies found that Egr-1 levels in the dorsal hippocampus do not vary with anxiety-like level in the rat, it is possible that another area of the hippocampus, the ventral pole, would show anxiety-dependent differences in gene expression. In recent years, there has been an increasing amount of evidence through lesion, gene expression, anatomical, and physiological studies suggesting that the dorsal and ventral hippocampus have distinct functions (Fanselow and Dong 2010; Bannerman et al. 2014). Generally, the dorsal hippocampus is important for spatial information processing, while ventral hippocampal activity may predominate during fear or anxiety-like states (Moser and Moser 1998; Fanselow and Dong 2010; Bannerman et al. 2014). The ventral hippocampus is a target for future studies.

\section{Prefrontal cortex}

Egr-1 expression patterns indicate the MPFC acts comparable to both the hippocampus and the amygdala. Similar to CA1, regardless of anxiety-like state, PL and IL Egr-1 increased in rats exposed to a novel context and in fear-conditioned rats compared with handled controls. Thus, it responds, like CA1, to the novelty of the chamber. Additionally, in low anxious rats PL and IL Egr-1 expression was greater after fear conditioning compared with the context rats. This is similar to the pattern of Egr-1 in the LA, and consistent with a recent studies demonstrating Egr-1 in both the PL and IL regions increases with exposure to a novel context, but show additional increases with contextual fear conditioning in a context preexposure facilitation paradigm (Asok et al. 2013; Chakraborty et al. 2016). However, in high anxious rats, novelty drives Egr-1 expression as much as fear conditioning does.

Regardless of whether activity in the MPFC is related to overt fear conditioning, it is clear that the $\mathrm{mPFC}$ is responsive to both novelty and fear conditioning. Other studies have also found similar results. Fos was increased following fear conditioning, while inhibiting Fos activity with an antisense oligonucleotide had no effect on fear acquisition (Morrow et al. 1999). Lesion and inactivation studies continue to produce mixed results in identifying whether $\mathrm{mPFC}$ regions are involved in the acquisition of conditioned fear, while a body of research supports the idea that the PL is involved in the expression of fear behaviors and the IL is involved in suppression and extinction of conditioned fear
(Rozeske et al. 2014; Giustino and Maren 2015). However, given anatomical connections to both the amygdala and hippocampus, and increases in activity markers during times of fear and novelty, it is clear that the mPFC is an intricate part of the circuitry for novelty and fear conditioning. The increase in mPFC Egr-1 activity in response to novel context may be a reflection of contextual processing similar to that of the hippocampus. Recent work showing that Arc is activated in the PL following context exposure supports this idea (Zelikowsky et al. 2014). The CA1 region of the dorsal hippocampus innervates the prelimbic and infralimbic regions of the mPFC (Thierry et al. 2000), and therefore, the increase of Egr-1 in the context-exposed animals may reflect contextual processing that is relayed from the hippocampus to the mPFC.

Functional connectivity between $\mathrm{mPFC}$ and amygdala activity has been shown to be different during fear and safety (Stujenske et al. 2014). During a fear cue (high state-like anxiety), $\gamma$ oscillations in both the basolateral amygdala and mPFC are low and $\theta$ is the dominate rhythm. In contrast, during a safety cue (low state-like anxiety), there is increased $\gamma$ power in both regions, enhanced mPFC to basolateral amygdala directionality, and enhanced PFC $\theta$ and basolateral amygdala $\gamma$ coupling. Thus, the mPFC and basolateral amygdala interact differently during fear and safety. Whether the Egr-1 expression patterns we find in low and high state anxiety-like rat is associated with differential connectivity patterns with fear and safety can be explored in future studies.

The mPFC may additionally receive information about cue salience from the amygdala to facilitate attention to stimuli (Gilmartin et al. 2014). As Egr-1 increases to a level greater than mere context exposure within the amygdala in low state-like anxiety rats, this activity may correlate with the mPFC increases seen in low state-like anxiety as well. Alternatively, activity within the mPFC may regulate higher-order processing by top-down regulation of the amygdala (Mechias et al. 2010). Within the amygdala and prefrontal cortex, increases in Egr-1 are seen in fear conditioning in the low anxiety-like group, increases that are masked by increases in Egr-1 to novel context exposure when anxiety-like levels are high. Disrupted functional connectivity between the amygdala and prefrontal cortex has been associated with increased anxiety behaviors in humans (Etkin and Wager 2007; Etkin 2009; Kim et al. 2011). It is evident is that activity within the mPFC is dependent both upon state anxiety level as well as fear learning.

\section{Conclusion}

Overall, the current experiments show that brain areas involved in processing overt fear are also active during anxiety-like states when experiencing novelty. However, each of the brain regions examined respond differently, indicating differential processing of the novel information. Furthermore, specifically for the inducible transcription factor $E g r-1$, its role in the amygdala is not confined to fear conditioning only, but it may also play a role in processing during ambiguous and uncertain situations, possibly through interactions with the medial prefrontal cortex.

\section{Materials and Methods}

\section{Animals}

A total of 112 male Sprague-Dawley rats (Envigo, Indianapolis, IN), weighing 225-250 g upon arrival, were used in all experiments. Rats were housed in pairs with ad libitum access to food and water and were maintained on a 12:12 h light:dark cycle. All animals were undisturbed for $1 \mathrm{wk}$ following arrival to allow for acclimation to the housing facility. All procedures were approved by the University of Delaware Institutional Animal Care and Use Committee. 


\section{Handling procedure}

For all experiments, rats were handled using the following protocol. Following the 1-wk acclimation, animals were handled for $5 \mathrm{~min}$ a day for $7 \mathrm{~d}$. Each day, animals were transported from the animal facility to the laboratory, and each animal was handled in turn by the same experimenter every day. For the $7 \mathrm{~d}$, animals were handled under one of two conditions. In the "noisy handling" condition, animals were handled while a movie played in the room at full volume. The movies chosen were The Rock and Bad Boys, and provided loud, intermittent, and unexpected bursts of noise (65-95 dB range) throughout the time handled. In the "quiet handling" condition, rats were handled with the same movies playing as in the noisy condition, but the television volume was muted, eliminating the loud, intermittent noise, and leaving a statically quiet room (60-65 $\mathrm{dB}$ range).

\section{Experiment 1: open field}

\section{Apparatus}

The open field consisted of a circular piece of Plexiglas $118 \mathrm{~cm}$ in diameter enclosed by a wall of poster board $26 \mathrm{~cm}$ tall. The field was sectioned into 32 squares $\sim 17 \mathrm{~cm}$ each. The open field was placed in the center of a brightly lit room (overhead room fluorescent lights were on, and two 60-W bulb lamps focused on the open field). A video camera was suspended above the open field, and a computer in an adjacent room, where the experimenter sat, recorded activity in the open field.

\section{Procedure}

The day following the noisy or quiet handling procedure, rats were transported to the laboratory and each rat was placed in the center of the field facing away from the experimenter and left to explore for $5 \mathrm{~min}$. The experimenter later scored the number of squares the rat entered during the 5-min test. Time (in seconds) spent in the innermost squares (four squares in the center) of the field was also scored. The field was cleaned with a $5 \%$ (vol/vol) ammonium hydroxide solution after each rat. Data for locomotion (number of squares entered) and anxiety-like behavior (time in innermost squares) were analyzed by one-factor ANOVAs.

\section{Experiment 2: contextual fear conditioning}

\section{Apparatus}

Contextual fear conditioning occurred in four identical testing chambers (S-R Chambers, San Diego Instruments) each consisting of an 8.6- $\mathrm{cm}$ diameter, $20-\mathrm{cm}$ long Plexiglas cylinder mounted in a Plexiglas base. Plexiglas doors dropped into slots at each end of the cylinder to keep the rat in the chamber. Rats were confined, but could move freely, as they could turn around in the chamber, and then face one of the two doors. The cylinder was housed within a Formica laminated particleboard sound-attenuating enclosure $(30 \mathrm{~cm} \times 30 \mathrm{~cm} \times 60 \mathrm{~cm})$. A grid floor inserted into each chamber was attached to a scrambled shocker (San Diego Instruments) and consisted of seven parallel stainless steel rods, spaced $1.5 \mathrm{~cm}$ apart, each bar measuring $4 \mathrm{~mm}$ in diameter. Delivery of footshock was controlled by computer using the San Diego Instruments software. A fan within the chamber provided a background noise level of $70 \mathrm{~dB}$. The testing occurred in a darkened room illuminated by a $25 \mathrm{~W}$ bulb located overhead in each chamber. Chamber doors were left open during conditioning to allow observation of behavior. The chambers were cleaned with a 5\% ammonium hydroxide solution after each session.

\section{Procedure}

To assess the effect of either noisy or quiet handling on fear conditioning, rats handled in either a noisy or quiet environment for $7 \mathrm{~d}$ and then randomly divided into two groups: context or contextual fear conditioned. Rats in the fear-conditioned group were placed in the experimental chambers and given a 3-min acclimation peri- od, followed by a 1 -sec $1.5-\mathrm{mA}$ footshock. They remained in the chamber for an additional $4 \mathrm{~min}$ and were then returned to their home cages. Rats assigned to the context group were placed in the chambers for the same 7-min session as the fear-conditioned rats, but did not receive a footshock. Twenty-four hours later, rats were placed back into the chambers for 4 min to assess retention. This was the last behavioral session for the context animals, as they tend to show very low or no freezing behavior at any time point. The conditioned animals, however, were placed back into the chambers at 24-h intervals for 4 min each for 3 more days to measure extinction. Freezing behavior was visually scored during the sessions for the 3 min prior to shock (preshock freezing), $4 \mathrm{~min}$ after the shock (post-shock freezing), and 4 min the following day (retention freezing) for animals in both the context and conditioned groups. Although animals in the context group were not given a footshock, freezing behavior during the 7-min training session was divided and scored similarly to the conditioned animals (i.e., pre- and post-shock). Freezing in the fear-conditioned animals continued to be measured for 4 min each on three subsequent days (extinction). Freezing behavior, commonly used as a behavioral index of fear in rats, is characterized by a crouching posture with a complete cessation of movement except that associated with respiration (Blanchard and Blanchard 1969). Each rat was scored as freezing or not every $10 \mathrm{sec}$, and percentage of time freezing was calculated for each animal at each time point ((no. of freezing observations/total observations) $\times 100)$. A repeatedmeasures ANOVA, one between (handling) and one within measure (freezing), followed by a Student-Newman-Keuls post hoc test was used to determine differences in freezing between groups and between handling conditions.

A second experiment was conducted using a $0.6-\mathrm{mA}$ footshock instead of a $1.5 \mathrm{~mA}$. A comparison of noisy and quiethandled animals was made following fear conditioning only. Rats that were exposed to the context without footshock were not included because they consistently show no freezing. Additionally, extinction tests were only given for $2 \mathrm{~d}$ because of the lower levels of freezing initially.

\section{Experiment 3: gene expression studies}

\section{Apparatus}

The testing chambers were the same as described in Experiment 2.

\section{Context exposure and contextual fear conditioning}

\section{Procedure}

Following $7 \mathrm{~d}$ of either noisy or quiet handling, rats in each condition were further divided into three groups (eight rats per group): handled (home cage controls), context (chamber exposure without footshock), and fear conditioned (contextually fear conditioned). On the day of the experiment, rats in the handled groups remained in their home cages in the handling room of the laboratory. Rats in the fear-conditioned group were contextually fear conditioned: rats were placed in the experimental chambers and given a 3-min acclimation period, followed by a 1 -sec $1.5-\mathrm{mA}$ footshock. They remained in the chamber for an additional $4 \mathrm{~min}$ and were then returned to their home cages. Rats assigned to the context group were placed in the chambers for the same 7-min session as the fearconditioned rats, but did not receive a footshock. Rats in the context and conditioned groups were never run together in the same session. When rats completed their sessions, they were returned to their home/transport cages in the laboratory and kept in a holding room. Thirty minutes following chamber exposure, rats in the context and conditioned groups were sacrificed. Rats in the handled group were sacrificed at the same time. All brains were processed for in situ hybridization of $E g r-1$. Freezing behavior was scored as described in Experiment 2.

\section{In situ hybridization}

Following decapitation, the brains were removed and flash-frozen in $-45^{\circ} \mathrm{C}$ isopentane and stored at $-80^{\circ} \mathrm{C}$. Sixteen micrometer 
coronal brain sections were cut on a cryostat (Jung CM3000, Leica) and mounted onto superfrost plus microscope slides (VWR). Two adjacent brain sections were placed on each slide. The slides were stored at $-80^{\circ} \mathrm{C}$ until processed for in situ hybridization. cRNA probes were transcribed from plasmids containing antisense cDNA codes for a 230-bp sequence of Egr-1 (gift from Jeffrey Milbrandt, Washington University, St. Louis, MO). The riboprobes were labeled using in vitro transcription with ${ }^{35}$ S-UTP ( 100 DPM/ $\mu \mathrm{g})$ using $\mathrm{T} 7$ polymerase Maxiscript (Ambion) according to the manufacturer's instructions.

In situ hybridization for each animal was performed on four consecutive brain sections containing the lateral nucleus of the amygdala, the dorsal hippocampus, and the medial prefrontal cortex. Sections were fixed in $4 \%$ formaldehyde in $1 \times$ phosphate buffered saline (PBS) and then rinsed in PBS. The sections were treated with $0.25 \%$ acetic anhydride in $0.1 \mathrm{M}$ triethanolamine for $10 \mathrm{~min}$ at room temperature. This was followed by dehydration in which the sections were treated with increasing concentrations of alcohol, defatted in chloroform, and then followed by another ethanol rinse. The sections were air-dried. ${ }^{35}$ S-labeled cRNA $(\sim 1 \times 100 \mathrm{DPM} /$ $\mu \mathrm{L}$ ) was added to $100 \mu \mathrm{L}$ of hybridization buffer (containing $20 \mathrm{mM}$ Tris- $\mathrm{HCl}$ ( $\mathrm{pH} 7.4$ ), 50\% formamide, $300 \mathrm{mM} \mathrm{NaCl}, 1 \mathrm{mM}$ EDTA $(\mathrm{pH} 8), 1 \times$ Denhardt's, $250 \mu \mathrm{g} / \mathrm{mL}$ yeast total RNA, $100 \mu \mathrm{g} / \mathrm{mL}$ salmon sperm DNA, $10 \%$ dextran sulfate, $100 \mathrm{mM}$ dithiothreitol, $0.1 \%$ sodium dodecyl sulfate, and $0.1 \%$ sodium thiosulfate). The slides were covered with glass coverslips and incubated in a humidified box overnight at $55^{\circ} \mathrm{C}$. The following day, the sections were rinsed four times for 5 min each in $4 \times$ saline sodium citrate (SSC). They were then treated with $20 \mu \mathrm{g} / \mathrm{mL}$ RNase A (Roche Applied Science) in an RNase buffer solution containing $0.5 \mathrm{M}$ $\mathrm{NaCl}, 1 \mathrm{mM}$ EDTA, $10 \mathrm{mM}$ Tris- $\mathrm{HCl}(\mathrm{pH}$ ) for $30 \mathrm{~min}$ at room temperature. The slides were then washed in decreasing concentrations of $1 \times, 0.5 \times$, and $0.1 \times$ SSC for 5 min each at room temperature. This was followed by two $30-\mathrm{min}$ washes in $0.1 \times \operatorname{SSC}$ at $65^{\circ} \mathrm{C}$. Finally, the slides were then washed in increasing concentrations of ethanol containing $300 \mathrm{mM}$ ammonium acetate, and allowed to air-dry. The slides were exposed to Kodak Biomax MR film for $2 \mathrm{~d} .{ }^{14} \mathrm{C}$ standards (Amersham) were also exposed to the film. The autoradiograms of in situ hybridization were digitized and converted to gray values using a Dage CCD video camera with the Image 64 program on an Apple Power Mac G4 and then analysed with the same program. The ImageJ program was used to subtract the background and measure the mean density of pixels within the area of interest. The gray values were converted to $\mathrm{nCi} / \mathrm{g}$ from the ${ }^{14} \mathrm{C}$ standards on each film. The densities of labeling of Egr-1 were statistically analyzed in the dorsolateral portion of the lateral nucleus of the amygdala, areas CA1, CA3, and dentate gyrus of the dorsal hippocampus, and the prelimbic and infralimbic regions of the medial prefrontal cortex. The densities of the right and left side of the brain for the four brain sections per animal were averaged into a single score for each brain region for each rat. The scores from each animal were normalized to percent of the mean handled group scores [ $(\mathrm{nCi} / \mathrm{g}$ of experimental group/ $\mathrm{nCi} / \mathrm{g}$ of handled group) $\times 100]$ to produce a relative change score. One-way ANOVAs were used to analyze the gene expression in each region separately. Level of statistical significance was set at $P<0.05$, and significant differences were further analyzed with Student-Newman-Keuls post hoc tests.

\section{Acknowledgments}

The study was supported by NSF grant IBN-0129809 awarded to J.B.R.

\section{References}

Asok A, Schreiber WB, Jablonski SA, Rosen JB, Stanton ME. 2013. Egr-1 increases in the prefrontal cortex following training in the context preexposure facilitation effect (CPFE) paradigm. Neurobiol Learn Mem 106: $145-153$.

Balderston NL, Schultz DH, Helmstetter FJ. 2011. The human amygdala plays a stimulus specific role in the detection of novelty. Neuroimage 55: 1889-1898.
Balderston NL, Schultz DH, Helmstetter FJ. 2013. The effect of threat on novelty evoked amygdala responses. PLOS ONE 8: e63220.

Bannerman DM, Sprengel R, Sanderson DJ, McHugh SB, Rawlins JNP, Monyer H, Seeburg PH. 2014. Hippocampal synaptic plasticity, spatial memory and anxiety. Nat Rev Neurosci 15: 181-192.

Barbelivien A, Herbeaux K, Oberling P, Kelche C, Galani R, Majchrzak M. 2006. Environmental enrichment increases responding to contextual cues but decreases overall conditioned fear in the rat. Behav Brain Res 169: 231-238.

Barlow DH, Ellard KK, Sauer-Zavala S. 2014. The origins of neuroticism. Perspect Psychol Sci 9: 481-496.

Beck CH, Fibiger HC. 1995. Conditioned fear-induced changes in behavior and in the expression of the immediate early gene c-fos: with and without diazepam pretreatment. I Neurosci 15: 709-720.

Benaroya Milshtein N, Hollander N, Apter A, Kukulansky T, Raz N, Wilf A, Yaniv I, Pick CG. 2004. Environmental enrichment in mice decreases anxiety, attenuates stress responses and enhances natural killer cell activity. Eur J Neurosci 20: 1341-1347.

Bishop SJ. 2007. Neurocognitive mechanisms of anxiety: an integrative account. Trends Cogn Sci (Regul Ed) 11: 307-316.

Bishop SJ. 2008. Neural mechanisms underlying selective attention to threat. Ann N Y Acad Sci 1129: 141-152.

Blackford JU, Avery SN, Shelton RC, Zald DH. 2009. Amygdala temporal dynamics: temperamental differences in the timing of amygdala response to familiar and novel faces. BMC Neurosci 10: 145.

Blackford JU, Buckholtz JW, Avery SN, Zald DH. 2010. A unique role for the human amygdala in novelty detection. Neuroimage 50: 1188-1193.

Blackford JU, Avery SN, Cowan RL, Shelton RC, Zald DH. 2011. Sustained amygdala response to both novel and newly familiar faces characterizes inhibited temperament. Soc Cogn Affect Neurosci 6: 621-629.

Blackford JU, Allen AH, Cowan RL, Avery SN. 2013. Amygdala and hippocampus fail to habituate to faces in individuals with an inhibited temperament. Soc Cogn Affect Neurosci 8: 143-150.

Blanchard RJ, Blanchard DC. 1969. Crouching as an index of fear. J Comp Physiol Psychol 67: 370-375.

Blanchette I, Richards A. 2003. Anxiety and the interpretation of ambiguous information: beyond the emotion-congruent effect. J Exp Psychol Gen 132: 294-309.

Blanchette I, Richards A, Cross A. 2007. Anxiety and the interpretation of ambiguous facial expressions: The influence of contextual cues. QJ Exp Psychol (Hove) 60: 1101-1115.

Briand LA, Robinson TE, Maren S. 2005. Enhancement of auditory fear conditioning after housing in a complex environment is attenuated by prior treatment with amphetamine. Learn Mem 12: 553-556.

Butler G, Mathews A. 1983. Cognitive processes in anxiety. Adv Behav Res Ther 5: 51-62.

Byrne A, Eysenck MW. 1993. Individual differences in positive and negative interpretive biases. Pers Individ Dif 14: 849-851.

Chakraborty T, Asok A, Stanton ME, Rosen JB. 2016. Variants of contextual fear conditioning induce differential patterns of Egr-1 activity within the young adult prefrontal cortex. Behav Brain Res 302: 122-130.

Clemenson GD, Lee SW, Deng W, Barrera VR, Iwamoto KS, Fanselow MS, Gage FH. 2015. Enrichment rescues contextual discrimination deficit associated with immediate shock. Hippocampus 25: 385-392.

Cruz FC, Koya E, Guez-Barber DH, Bossert JM, Lupica CR, Shaham Y, Hope BT. 2013. New technologies for examining the role of neuronal ensembles in drug addiction and fear. Nat Rev Neurosci 14: 743-754.

Daselaar SM, Fleck MS, Cabeza R. 2006. Triple dissociation in the medial temporal lobes: recollection, familiarity, and novelty. J Neurophysiol 96: 1902-1911.

Daumas S, Halley H, Francés B, Lassalle J-M. 2005. Encoding, consolidation, and retrieval of contextual memory: differential involvement of dorsal CA3 and CA1 hippocampal subregions. Learn Mem 12: 375-382.

Davis M. 1997. Neurobiology of fear responses: the role of the amygdala. J Neuropsychiatry Clin Neurosci 9: 382-402.

Davis M, Whalen PJ. 2001. The amygdala: vigilance and emotion. Mol Psychiatry 6: 13-34.

Davis S, Bozon B, Laroche S. 2003. How necessary is the activation of the immediate early gene zif268 in synaptic plasticity and learning? Behav Brain Res 142: 17-30.

Davis FC, Neta M, Kim MJ, Moran JM, Whalen PJ. 2016. Interpreting ambiguous social cues in unpredictable contexts. Soc Cogn Affect Neurosci 11: $775-782$.

Dobrakovová M, Kvetňanský R, Opršalová Z. 1993. Specificity of the effect of repeated handling on sympathetic-adrenomedullary and pituitary-adrenocortical activity in rats. Psychoneuroendocrinology 18: $163-174$.

Duffy SN, Craddock KJ, Abel T, Nguyen PV. 2001. Environmental enrichment modifies the PKA-dependence of hippocampal LTP and improves hippocampus-dependent memory. Learn Mem 8: 26-34.

Ennaceur A. 2014. Tests of unconditioned anxiety - Pitfalls and disappointments. Physiol Behav 135: 55-71. 
Etkin A. 2009. Functional neuroanatomy of anxiety: a neural circuit perspective. In Behavioral neuroscience of motivation (ed. Simpson EH, Balsam PD), Vol. 2 of Current Topics in Behavioral Neurosciences, pp. 251-277. Springer Berlin Heidelberg, Berlin, Heidelberg.

Etkin A, Wager TD. 2007. Functional neuroimaging of anxiety: a meta-analysis of emotional processing in PTSD, social anxiety disorder, and specific phobia. Am J Psychiatry 164: 1476-1488.

Eysenck MW, Mogg K, May J, Richards A, Mathews A. 1991. Bias in interpretation of ambiguous sentences related to threat in anxiety. J Abnorm Psychol 100: 144-150.

Fanselow MS, Dong H-W. 2010. Are the dorsal and ventral hippocampus functionally distinct structures? Neuron 65: 7-19.

Fernández-Teruel A, Driscoll P, Gil L, Aguilar R, Tobeña A, Escorihuela RM. 2002. Enduring effects of environmental enrichment on novelty seeking, saccharin and ethanol intake in two rat lines (RHA/Verh and RLA/Verh) differing in incentive-seeking behavior. Pharmacol Biochem Behav 73: 225-231.

Fischer H, Wright CI, Whalen PJ, McInerney SC, Shin LM, Rauch SL. 2003. Brain habituation during repeated exposure to fearful and neutral faces: a functional MRI study. Brain Res Bull 59: 387-392.

Fried I, MacDonald KA, Wilson CL. 1997. Single neuron activity in human hippocampus and amygdala during recognition of faces and objects. Neuron 18: 753-765.

Furmark T, Fischer H, Wik G, Larsson M, Fredrikson M. 1997. The amygdala and individual differences in human fear conditioning. Neuroreport 8: 3957-3960.

Gilmartin MR, Balderston NL, Helmstetter FJ. 2014. Prefrontal cortical regulation of fear learning. Trends Neurosci 37: 455-464.

Giustino TF, Maren S. 2015. The role of the medial prefrontal cortex in the conditioning and extinction of fear. Front Behav Neurosci 9: 298.

Gouty-Colomer LA, Hosseini B, Marcelo IM, Schreiber J, Slump DE, Yamaguchi S, Houweling AR, Jaarsma D, Elgersma Y, Kushner SA. 2015 Arc expression identifies the lateral amygdala fear memory trace. Mol Psychiatry 21: 364-375.

Grunwald T, Lehnertz K, Heinze HJ, Helmstaedter C, Elger CE. 1998. Verbal novelty detection within the human hippocampus proper. Proc Natl Acad Sci 95: 3193-3197.

Guzowski JF, McNaughton BL, Barnes CA, Worley PF. 1999. Environment-specific expression of the immediate-early gene Arc in hippocampal neuronal ensembles. Nat Neurosci 2: 1120-1124.

Halberstadt JB, Niedenthal PM, Kushner J. 1995. Resolution of lexical ambiguity by emotional state. Psychol Sci 6: 278-282.

Hall J, Thomas KL, Everitt BJ. 2000. Rapid and selective induction of BDNF expression in the hippocampus during contextual learning. Nat Neurosci 3: $533-535$.

Han JH, Kushner SA, Yiu AP, Cole CJ, Matynia A, Brown RA, Neve RL, Guzowski JF, Silva AJ, Josselyn SA. 2007. Neuronal competition and selection during memory formation. Science 316: 457-460.

Herry C, Bach DR, Esposito F, Di Salle F, Perrig WJ, Scheffler K, Lüthi A, Seifritz E. 2007. Processing of temporal unpredictability in human and animal amygdala. J Neurosci 27: 5958-5966.

Hsu M, Bhatt M, Adolphs R, Tranel D, Camerer CF. 2005. Neural systems responding to degrees of uncertainty in human decision-making. Science 310: $1680-1683$.

Janak PH, Tye KM. 2015. From circuits to behaviour in the amygdala. Nature 517: 284-292.

Jenkins TA, Amin E, Pearce JM, Brown MW, Aggleton JP. 2004. Novel spatial arrangements of familiar visual stimuli promote activity in the rat hippocampal formation but not the parahippocampal cortices: a c-fos expression study. Neuroscience 124: 43-52.

Josselyn SA, Köhler S, Frankland PW. 2015. Finding the engram. Nat Rev Neurosci 16: 521-534.

Kim JJ, Fanselow MS, DeCola JP, Landeira-Fernandez J. 1992. Selective impairment of long-term but not short-term conditional fear by the N-methyl-D-aspartate antagonist APV. Behav Neurosci 106: 591-596.

Kim MJ, Loucks RA, Palmer AL, Brown AC, Solomon KM, Marchante AN, Whalen PJ. 2011. The structural and functional connectivity of the amygdala: from normal emotion to pathological anxiety. Behav Brain Res 223: 403-410.

Kirwan CB, Shrager Y, Squire LR. 2009. Medial temporal lobe activity can distinguish between old and new stimuli independently of overt behavioral choice. Proc Natl Acad Sci 106: 14617-14621.

Knapska E, Kaczmarek L. 2004. A gene for neuronal plasticity in the mammalian brain: Zif268/Egr-1/NGFI-A/Krox-24/TIS8/ZENK? Prog Neurobiol 74: 183-211.

LaBar KS, Gatenby JC, Gore JC, Ledoux JE, Phelps EA. 1998. Human amygdala activation during conditioned fear acquisition and extinction: a mixed-trial fMRI study. Neuron 20: 937-945.

Larson CL, Schaefer HS, Siegle GJ, Jackson CAB, Anderle MJ, Davidson RJ. 2006. Fear is fast in phobic individuals: amygdala activation in response to fear-relevant stimuli. Biol Psychiatry 60: 410-417.
Larsson F, Winblad B, Mohammed AH. 2002. Psychological stress and environmental adaptation in enriched vs. impoverished housed rats. Pharmacol Biochem Behav 73: 193-207.

LeDoux JE. 2000. Emotion circuits in the brain. Annu Rev Neurosci 23: $155-184$.

LeDoux J. 2007. The amygdala. Curr Biol 17: R868-R874.

Lee I, Kesner RP. 2004. Differential contributions of dorsal hippocampal subregions to memory acquisition and retrieval in contextual fear-conditioning. Hippocampus 14: 301-310.

Lee JLC, Everitt BJ, Thomas KL. 2004. Independent cellular processes for hippocampal memory consolidation and reconsolidation. Science 304: 839-843.

Lever C, Burton S, Jeewajee A, Wills TJ, Cacucci F, Burgess N, O'Keefe J. 2010. Environmental novelty elicits a later $\theta$ phase of firing in CA1 but not subiculum. Hippocampus 20: 229-234.

Mackler SA, Brooks BP, Eberwine JH. 1992. Stimulus-induced coordinate changes in mRNA abundance in single postsynaptic hippocampal CA1 neurons. Neuron 9: 539-548.

Maddox SA, Monsey MS, Schafe GE. 2011. Early growth response gene 1 (Egr-1) is required for new and reactivated fear memories in the lateral amygdala. Learn Mem 18: 24-38.

Malkani S, Rosen JB. 2000. Specific induction of early growth response gene 1 in the lateral nucleus of the amygdala following contextual fear conditioning in rats. Neuroscience 97: 693-702.

Malkani S, Wallace KJ, Donley MP, Rosen JB. 2004. An egr-1 (zif268) antisense oligodeoxynucleotide infused into the amygdala disrupts fear conditioning. Learn Mem 11: 617-624.

Maren S. 2001. Neurobiology of Pavlovian fear conditioning. Annu Rev Neurosci 24: 897-931.

Maren S, Fanselow MS. 1996. The amygdala and fear conditioning: has the nut been cracked? Neuron 16: 237-240.

Mathews A, Mackintosh B. 1998. A cognitive model of selective processing in anxiety. Cognit Ther Res 22: 539-560.

Mathews A, Richards A, Eysenck M. 1989. Interpretation of homophones related to threat in anxiety states. J Abnorm Psychol 98: 31-34.

McCarthy MM, Felzenberg E, Robbins A, Pfaff DW, Schwartz-Giblin S. 1995. Infusions of diazepam and allopregnanolone into the midbrain central gray facilitate open-field behavior and sexual receptivity in female rats. Horm Behav 29: 279-295.

Mcnaughton BL, Battaglia FP, Jensen O, Moser EI, Moser M-B. 2006. Path integration and the neural basis of the 'cognitive map'. Nat Rev Neurosci 7: 663-678.

Mechias M-L, Etkin A, Kalisch R. 2010. A meta-analysis of instructed fear studies: implications for conscious appraisal of threat. Neuroimage 49: 1760-1768.

Menon V, White CD, Eliez S, Glover GH, Reiss AL. 2000. Analysis of a distributed neural system involved in spatial information, novelty, and memory processing. Hum Brain Mapp 11: 117-129.

Mogg K, Bradley BP. 1998. A cognitive-motivational analysis of anxiety. Behav Res Ther 36: 809-848.

Morrow BA, Elsworth JD, Inglis FM, Roth RH. 1999. An antisense oligonucleotide reverses the footshock-induced expression of fos in the rat medial prefrontal cortex and the subsequent expression of conditioned fear-induced immobility. J Neurosci 19: 5666-5673.

Moser M-B, Moser EI. 1998. Functional differentiation in the hippocampus. Hippocampus 8: 608-619.

Moser EI, Kropff E, Moser M-B. 2008. Place cells, grid cells, and the brain's spatial representation system. Annu Rev Neurosci 31: 69-89.

Niedenthal PM, Setterlund MB. 1994. Emotion congruence in perception. Pers Soc Psychol Bull 20: 401-411.

Niedenthal PM, Setterlund JBHMB. 1997. Being happy and seeing "happy": emotional state mediates visual word recognition. Cogn Emot 11: 403-432.

Öhman A, Soares JJF. 1994. 'Unconscious anxiety': phobic responses to masked stimuli. J Abnorm Psychol 103: 231-240.

Ostroff LE, Cain CK, Bedont J, Monfils MH, LeDoux JE. 2010. Fear and safety learning differentially affect synapse size and dendritic translation in the lateral amygdala. Proc Natl Acad Sci 107: 9418-9423.

Ousdal OT, Andreassen OA, Server A, Jensen J. 2014. Increased amygdala and visual cortex activity and functional connectivity towards stimulus novelty is associated with state anxiety. PLoS One 9: e96146.

Papa M, Pellicano MP, Welzl H, Sadile AG. 1993. Distributed changes in c-Fos and c-Jun immunoreactivity in the rat brain associated with arousal and habituation to novelty. Brain Res Bull 32: 509-515.

Paxinos G, Watson C. 1998. The rat brain in stereotaxic coordinates. Academic, San Diego.

Paylor R, Spencer C, Yuva-Paylor L, Pieke-Dahl S. 2006. The use of behavioral test batteries, II: effect of test interval. Physiol Behav 87: 95-102.

Pedersen WS, Balderston NL, Miskovich TA, Belleau EL, Helmstetter FJ, Larson CL. 2017. The effects of stimulus novelty and negativity on BOLD activity in the amygdala, hippocampus, and bed nucleus of the stria terminalis. Soc Cogn Affect Neurosci 12: 748-757. 
Peña Y, Prunell M, Dimitsantos V, Nadal R, Escorihuela R. 2006. Environmental enrichment effects in social investigation in rats are gender dependent. Behav Brain Res 174: 181-187.

Phelps EA, O'Connor KJ, Gatenby JC, Gore JC, Grillon C, Davis M. 2001. Activation of the left amygdala to a cognitive representation of fear. Nat Neurosci 4: 437-441.

Pietropaolo S, Feldon J, Yee BK. 2014. Environmental enrichment eliminates the anxiety phenotypes in a triple transgenic mouse model of Alzheimer's disease. Cogn Affect Behav Neurosci 14: 996-1008.

Ploski JE, Park KW, Ping J, Monsey MS, Schafe GE. 2010. Identification of plasticity-associated genes regulated by Pavlovian fear conditioning in the lateral amygdala. J Neurochem 112: 636-650.

Richards A, French CC, Calder AJ, Webb B, Fox R, Young AW. 2002. Anxiety-related bias in the classification of emotionally ambiguous facial expressions. Emotion 2: 273-287.

Río-Álamos C, Oliveras I, Piludu MA, Gerbolés C, Cañete T, Blázquez G, Lope-Piedrafita S, Martínez-Membrives E, Torrubia R, Tobeña A, et al. 2017. Neonatal handling enduringly decreases anxiety and stress responses and reduces hippocampus and amygdala volume in a genetic model of differential anxiety: behavioral-volumetric associations in the Roman rat strains. Eur Neuropsychopharmacol 27: 146-158.

Roberts LA, Higgins MJ, O'Shaughnessy CT, Stone TW, Morris BJ. 1996. Changes in hippocampal gene expression associated with the induction of long-term potentiation. Brain Res Mol Brain Res 42: 123-127.

Rogan MT, Leon KS, Perez DL, Kandel ER. 2005. Distinct neural signatures for safety and danger in the amygdala and striatum of the mouse. Neuron 46: 309-320.

Romanelli P, Di Matteo L, Cobellis G, Varriale B, Menegazzi M, Gironi Carnevale U, Ruocco LA, Sadile AG. 2007. Transcription factor expression, RNA synthesis and NADPH-diaphorase across the rat brain and exposure to spatial novelty. Behav Brain Res 184: 91-100.

Rosen JB. 2004. The neurobiology of conditioned and unconditioned fear: a neurobehavioral system analysis of the amygdala. Behav Cogn Neurosci Rev 3: $23-41$.

Rosen JB, Donley MP. 2006. Animal studies of amygdala function in fear and uncertainty: relevance to human research. Biol Psychol 73: 49-60.

Rosen JB, Schulkin J. 1998. From normal fear to pathological anxiety. Psychol Rev 105: 325-350.

Rosen JB, Fanselow MS, Young SL, Sitcoske M, Maren S. 1998. Immediate-early gene expression in the amygdala following footshock stress and contextual fear conditioning. Brain Res 796: 132-142.

Rosen JB, Malkani S, Wallace K, Thompson B. 1999. A neurobehavioral system approach in rats to study the molecular biology of fear. In Molecular-genetic techniques for brain and behavior research (ed. Cursio W, Gerlai R.), pp. 674-695. Elsevier, New York.

Rozeske RR, Valerio S, Chaudun F, Herry C. 2014. Prefrontal neuronal circuits of contextual fear conditioning. Genes Brain Behav 14: 22-36.

Sander D, Grafman J, Zalla T. 2003. The human amygdala: an evolved system for relevance detection. Rev Neurosci 14: 303-316.

Sangha S, Chadick JZ, Janak PH. 2013. Safety encoding in the basal amygdala. J Neurosci 33: 3744-3751.

Satpute AB, Wager TD, Cohen-Adad J, Bianciardi M, Choi J-K, Buhle JT, Wald LL, Barrett LF. 2013. Identification of discrete functional subregions of the human periaqueductal gray. Proc Natl Acad Sci 110: 17101-17106.
Schultz W, Preuschoff K, Camerer C, Hsu M, Fiorillo CD, Tobler PN, Bossaerts P. 2008. Explicit neural signals reflecting reward uncertainty. Philos Trans R Soc Lond, B Biol Sci 363: 3801-3811.

Schwartz CE, Wright CI, Shin LM, Kagan J, Whalen PJ, McMullin KG, Rauch SL. 2003. Differential amygdalar response to novel versus newly familiar neutral faces: a functional MRI probe developed for studying inhibited temperament. Biol Psychiatry 53: 854-862.

Shimizu E, Tang Y-P, Rampon C, Tsien JZ. 2000. NMDA Receptor-dependent synaptic reinforcement as a crucial process for memory consolidation. Science 290: $1170-1174$.

Somerville LH, Kim H, Johnstone T, Alexander AL, Whalen PJ. 2004. Human amygdala responses during presentation of happy and neutral faces: correlations with state anxiety. Biol Psychiatry 55: 897-903.

Stujenske JM, Likhtik E, Topiwala MA, Gordon JA. 2014. Fear and safety engage competing patterns of $\theta-\gamma$ coupling in the basolateral amygdala. Neuron 83: 919-933.

Tang YP, Wang H, Feng R, Kyin M, Tsien JZ. 2001. Differential effects of enrichment on learning and memory function in NR2B transgenic mice. Neuropharmacology 41: 779-790.

Thierry AM, Gioanni Y, Dégénétais E, Glowinski J. 2000. Hippocampo-prefrontal cortex pathway: Anatomical and electrophysiological characteristics. Hippocampus 10: 411-419.

Tulving E, Markowitsch HJ, Craik F, Habib R, Houle S. 1996. Novelty and familiarity activations in PET studies of memory encoding and retrieval. Cereb Cortex 6: 71-79.

Vazdarjanova A, Guzowski JF. 2004. Differences in hippocampal neuronal population responses to modifications of an environmental context: evidence for distinct, yet complementary, functions of CA3 and CA1 ensembles. J Neurosci 24: 6489-6496.

Veyrac A, Besnard A, Caboche J, Davis S, Laroche S. 2014. The transcription factor zif268/egr1, brain plasticity, and memory. Prog Mol Biol Transl Sci 122: $89-129$.

Wei F, Xu ZC, Qu Z, Milbrandt J, Zhuo M. 2000. Role of Egr1 in hippocampal synaptic enhancement induced by tetanic stimulation and amputation. J Cell Biol 149: 1325-1334.

Whalen PJ. 1998. Fear, vigilance, and ambiguity: Initial neuroimaging studies of the human amygdala. Curr Dir Psychol Sci 7: 177-188.

Widman DR, Abrahamsen GC, Rosellini RA. 1992. Environmental enrichment: the influences of restricted daily exposure and subsequent exposure to uncontrollable stress. Physiol Behav 51: 309-318.

Wright CI, Martis B, Schwartz CE, Shin LM, Fischer H H, McMullin K, Rauch SL. 2003. Novelty responses and differential effects of order in the amygdala, substantia innominata, and inferior temporal cortex. Neuroimage 18: 660-669.

Wright CI, Negreira A, Gold AL, Britton JC, Williams D, Barrett LF. 2008. Neural correlates of novelty and face-age effects in young and elderly adults. Neuroimage 42: 956-968.

Zelikowsky M, Hersman S, Chawla MK, Barnes CA, Fanselow MS. 2014. Neuronal ensembles in amygdala, hippocampus, and prefrontal cortex track differential components of contextual fear. J Neurosci 34: 8462-8466.

Received March 17, 2017; accepted in revised form May 8, 2017. 


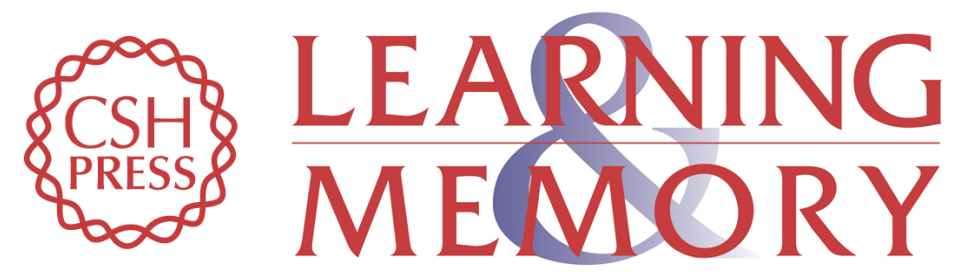

\section{Novelty and fear conditioning induced gene expression in high and low states of anxiety}

Melanie P. Donley and Jeffrey B. Rosen

Learn. Mem. 2017, 24:

Access the most recent version at doi:10.1101/Im.044289.116

References This article cites 121 articles, 19 of which can be accessed free at: http://learnmem.cshlp.org/content/24/9/449.full.html\#ref-list-1

Creative This article is distributed exclusively by Cold Spring Harbor Laboratory Press for the Commons License first 12 months after the full-issue publication date (see

http://learnmem.cshlp.org/site/misc/terms.xhtml). After 12 months, it is available under a Creative Commons License (Attribution-NonCommercial 4.0 International), as described at http://creativecommons.org/licenses/by-nc/4.0/.

Email Alerting Receive free email alerts when new articles cite this article - sign up in the box at the Service top right corner of the article or click here. 